\title{
Bulk parameterization of air-sea fluxes for Tropical Ocean- Global Atmosphere Coupled-Ocean Atmosphere Response Experiment
}

\author{
C. W. Fairall, ${ }^{1}$ E. F. Bradley, ${ }^{2}$ D. P. Rogers, ${ }^{3}$ J. B. Edson, ${ }^{4}$ and G. S. Young ${ }^{5}$
}

\begin{abstract}
This paper describes the various physical processes relating near-surface atmospheric and oceanographic bulk variables; their relationship to the surface fluxes of momentum, sensible heat, and latent heat; and their expression in a bulk flux algorithm. The algorithm follows the standard Monin-Obukhov similarity approach for near-surface meteorological measurements but includes separate models for the ocean's cool skin and the diurnal warm layer, which are used to derive true skin temperature from the bulk temperature measured at some depth near the surface. The basic structure is an outgrowth of the Liu-Katsaros-Businger [Liu et al., 1979] method, with modifications to include a different specification of the roughness/stress relationship, a gustiness velocity to account for the additional flux induced by boundary layer scale variability, and profile functions obeying the convective limit. Additionally, we have considered the contributions of the sensible heat carried by precipitation and the requirement that the net dry mass flux be zero (the so-called Webb correction [Webb et al., 1980]). The algorithm has been tuned to fit measurements made on the R/V Moana Wave in the three different cruise legs made during the Coupled Ocean-Atmosphere Response Experiment. These measurements yielded 1622 fifty-min averages of fluxes and bulk variables in the wind speed range from 0.5 to $10 \mathrm{~m} \mathrm{~s}^{-1}$. The analysis gives statistically reliable values for the Charnock [1955] constant $(\alpha=0.011)$ and the gustiness parameter $(\beta=1.25)$. An overall mean value for the latent heat flux, neutral bulk-transfer coefficient was $1.11 \times 10^{-3}$, declining slightly with increasing wind speed. Mean values for the sensible and latent heat fluxes were 9.1 and $103.5 \mathrm{~W} \mathrm{~m}^{-2}$; mean values for the Webb and rain heat fluxes were 2.5 and $4.5 \mathrm{~W} \mathrm{~m}^{-2}$. Accounting for all factors, the net surface heat transfer to the ocean was $17.9 \pm 10 \mathrm{~W} \mathrm{~m}^{-2}$.
\end{abstract}

\section{Introduction}

The importance of air-sea interaction to the Earth's climate is widely appreciated. The pivotal role of the tropical oceans in climate and interannual climate variability led to the establishment of the Tropical Ocean-Global Atmosphere (TOGA) program; the subsequent identification of the dominance of the Pacific Ocean in this variability resulted in the Coupled Ocean-Atmosphere Response Experiment (COARE) [World Climate Research Program (WCRP), 1990; Webster and Lukas, 1992]. The interfacial fluxes are one of three elements of the COARE program. The COARE science plan [WCRP, 1990, pp. A7-A8]

\footnotetext{
'Environmental Technology Laboratory, NOAA, Boulder, Colorado.

${ }^{2}$ Centre for Environmental Mechanics, Commonwealth Scientific and Industrial Research Organization, Canberra, Australian Capital Territory, Australia.

${ }^{3}$ Physical Oceanography Research Division, Scripps Institute of Oceanography, La Jolla, California.

${ }^{4}$ Applied Ocean Physics and Engineering Department, Woods Hole Oceanographic Institution, Woods Hole, Massachusetts.

${ }^{5}$ Department of Meteorology, Pennsylvania State University, University Park.
}

Copyright 1996 by the American Geophysical Union.

Paper number 95JC03205.

0148-0227/96/95JC-03205\$05.00 identifies several fundamental gaps in our knowledge relevant to fluxes:

Atmospheric response in models is extremely sensitive to SST variations, especially where SST is warm. However, ocean models almost universally predict temperatures which are too warm, probably associated with poor assessments of heat, momentum, and moisture fluxes to the ocean and atmosphere.

The heat balance of the warm pool region of the western Pacific is poorly known with discrepancies as large as $80 \mathrm{~W} \mathrm{~m}^{-2}$. The relative involvement of the slowly evolving atmosphere or the higher-frequency, more episodic, equatorial events is not understood.

Webster and Lukas [1992, p. 1394] emphasized that "the variation of fluxes between the ocean and the atmosphere is very sensitive to the choice of parameterization, especially in low wind regimes." This has been verified by Miller et al. [1992], who found dramatic improvements in simulated tropical phenomena by strengthening the air-sea coupling in the light-wind regime. Furthermore, observational problems in the climatological database, particularly the air-sea temperature difference [Lukas, 1989], the strong boundary layer diurnal cycle in light winds, and the unknown sensible cooling associated with precipitation, represent additional uncertainties in assessing the surface energy balance of the warm pool. In summary, our ability to diagnose, simulate, 
and predict climate and climate variability is impaired by a general lack of high-quality data in the region and inadequate parameterizations of air-sea fluxes.

\subsection{Scope of This Paper}

This paper is concerned with the estimation of air-sea fluxes from bulk variables, with a focus on a specific algorithm developed for the TOGA COARE investigators. Following background material on fluxes and similarity theory, we discuss the representation of the near-surface transfer processes in terms of the surface roughness parameters; theoretical issues associated with extending traditional methods to the light-wind, convective regime; the proper thermodynamic constants for the computation of the fluxes; and the estimation of the rainfall contribution to surface cooling (section 2). In section 3 we touch briefly on several measurement issues: the special problem of flux measurements from ships, the accuracy requirements for bulk variables, and a method to correct bulk water temperatures to obtain the true interfacial sea surface temperature (SST). The actual procedure used in the present algorithm is found in section 4.2; readers familiar with the theory of turbulent flux measurement might choose to refer immediately to this section and use it as a guide to the preceding development. A comparison of the algorithm with the Moana Wave COARE data is given in section 5 , including an analysis of the relative contributions to the latent heat flux by stability and gustiness corrections. Our conclusions are given in section 6.

\subsection{Bulk Flux Estimations}

Simultaneous flux and bulk meteorological variable measurements combined with laboratory studies of air-sea transfer processes are used to develop the bulk formulas and transfer coefficients. The classic reviews on this subject [Garratt, 1977; Smith, 1988] reveal a substantial midlatitude bias in the field measurements, with most of the data obtained in the 4-15 $\mathrm{m} \mathrm{s}^{-1}$ wind speed regime. The majority of the data is also from offshore towers, coastal areas, and other shallow water regimes. Uncertainties in the average neutral coefficients as a function of wind speed remain the critical question. Blanc's [1985] study showed a factor of 2 variation in suggested values for the humidity transfer coefficient with a consensus uncertainty of about $30 \%$. Note that a $10 \%$ uncertainty in this transfer coefficient results in a $10 \mathrm{~W} \mathrm{~m}^{-2}$ uncertainty in the latent heat flux and thus the surface energy budget of the warm pool.

In low wind speed regimes it is necessary to account for buoyancy effects on turbulent transport, and standard stability-dependent bulk schemes [e.g., Liu et al., 1979; Smith, 1988] have shown good performance in the tropics [Bradley et al., 1991]. However, a careful analysis [Godfrey and Beljaars, 1991] has shown these schemes to become singular at winds speeds below about $0.5 \mathrm{~m} \mathrm{~s}^{-1}$. This occurs when a basic similarity profile assumption (that the roughness length is much smaller than the Monin-Obukhov length) is violated. Godfrey and Beljaars [1991] showed that this singularity can be eliminated by adding a "gustiness" velocity $w_{g}$ related to the normal convective scaling velocity, which accounts for the fact that the amplitude of the mean wind vector does not properly characterize the mean wind speed in light winds. Because 1-hour average point winds of less than $4 \mathrm{~m} \mathrm{~s}^{-1}$ occur about half of the time in the COARE region, particular attention must be paid to this problem. Recent experimental studies in the COARE region have shown unequivocally that the scalar fluxes do not go to zero in the limit of zero mean wind [Bradley et al., 1991; Fujitani, 1992; Young et al., 1992; Bradley et al., 1993; Greenhut and Khalsa, 1995].

\section{Theory}

\subsection{Background}

The turbulent fluxes of sensible heat $H_{s}$, latent heat $H_{l}$, and stress $\tau$ components are defined by the normal Reynolds averages,

$$
\begin{aligned}
H_{s} & =\rho_{a} c_{p a} \overline{w^{\prime} T^{\prime}}=-\rho_{a} c_{p a} u_{*} T_{*} \\
H_{l} & =\rho_{a} L_{e} \overline{w^{\prime} q^{\prime}}=-\rho_{a} L_{e} u_{*} q_{*} \\
\tau & =\rho_{a} \overline{w^{\prime} u^{\prime}}=-\rho_{a} u_{*}^{2}
\end{aligned}
$$

where $w^{\prime}, T^{\prime}, q^{\prime}$, and $u^{\prime}$ represent the turbulent fluctuations of vertical wind, temperature, water vapor mixing ratio, and the streamwise component of horizontal wind, respectively; $T_{*}, q_{*}$, and $u_{*}$ are the related Monin-Obukhov similarity (MOS) scaling parameters [Panofsky and Dutton, 1984; Geernaert, 1990]. The overbar denotes an ensemble average but, in practice, is usually a time or space average.

The standard bulk expressions for the scalar fluxes and stress components are

$$
\begin{aligned}
& H_{s}=\rho_{a} c_{p a} C_{h} S\left(T_{s}-\theta\right) \\
& H_{t}=\rho_{a} L_{e} C_{e} S\left(q_{s}-q\right) \\
& \tau_{t}=\rho_{a} C_{d} S\left(u_{s t}-u_{1}\right)
\end{aligned}
$$

where $C_{d}, C_{h}$, and $C_{e}$ are the transfer coefficients for stress, sensible heat, and latent heat, respectively; $\theta$ is the potential temperature, $q$ is the water vapor mixing ratio, and $u_{I}$ is one of the horizontal wind components relative to the fixed Earth, each measured at some atmospheric reference height $z_{r}$ and averaged as in (1). $S$ is the average value of the wind speed relative to the sea surface at $z_{r} ; T_{s}$ is the sea surface interface temperature; $u_{s t}$ is the surface current; and $q_{s}$ is the interfacial value of the water vapor mixing ratio that is computed from the saturation mixing ratio for pure water at the SST,

$$
q_{s}=0.98 q_{\mathrm{sal}}\left(T_{s}\right)
$$

Alternatively, we may measure the wind components relative to the sea surface, in which case the $u_{s t}$ terms are zero. Following Sverdrup et al. [1942], the factor of 0.98 multiplying the saturation specific humidity of the SST takes into account the reduction in vapor pressure caused by a typical salinity of 34 parts per thousand. Note that

$$
\begin{aligned}
& \theta=T+0.0098 z_{r} \\
& q=\operatorname{RH} q_{s}(T)
\end{aligned}
$$

where $T$ is the air temperature at $z_{r}$ and $\mathrm{RH}$ is the relative humidity. 


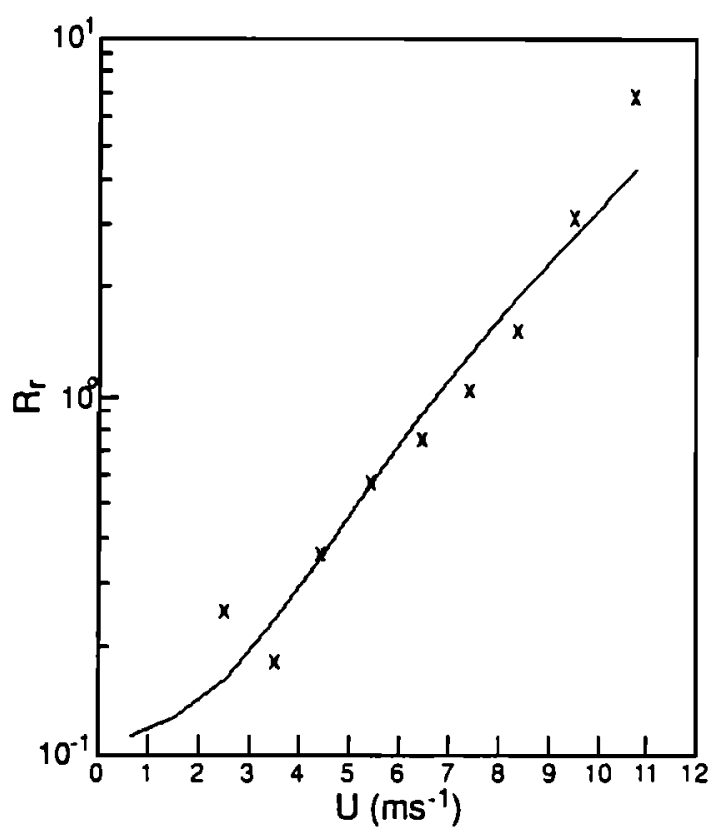

Figure 1. Roughness Reynolds number $R_{r}$ as a function of the $10-\mathrm{m}$ wind speed for the R/V Moana Wave Coupled Ocean-Atmosphere Response Experiment (COARE) data. The data have been averaged in wind speed bins with $1 \mathrm{~m} \mathrm{~s}^{-1}$ bin widths. The solid line is the COARE 2.0 algorithm result, and the crosses are computed from the mean inertialdissipation values for stress.

The transfer coefficients in (2) are partitioned into individual profile components,

$$
\begin{aligned}
& C_{h}=c_{T}^{1 / 2} c_{d}^{1 / 2} \\
& C_{e}=c_{q}^{1 / 2} c_{d}^{1 / 2} \\
& C_{d}=c_{d}^{1 / 2} c_{d}^{1 / 2}
\end{aligned}
$$

which are themselves functions of the fluxes in a manner described by MOS surface-layer theory [Panofsky and Dutton, 1984; Geernaert, 1990],

$$
\begin{aligned}
& c_{T}^{1 / 2}=c_{T n}^{1 / 2} /\left[1-\frac{c_{T_{n}}^{1 / 2}}{a \kappa} \Psi_{h}(\xi)\right] \\
& c_{q}^{1 / 2}=c_{q n}^{1 / 2} /\left[1-\frac{c_{q n}^{1 / 2}}{a \kappa} \Psi_{h}(\xi)\right] \\
& c_{d}^{1 / 2}=c_{d n}^{1 / 2} /\left[1-\frac{c_{d n}^{1 / 2}}{\kappa} \Psi_{u}(\xi)\right]
\end{aligned}
$$

Here $\mathrm{K}$ is the von Kármán constant (0.4), $a$ accounts for the difference in scalar and velocity von Kármán constants, $\psi$ is the MOS profile function (assumed the same for temperature and humidity), and $\xi=z_{r} / L$, where

$$
L^{-1}=\frac{\kappa g}{T}\left(T_{*}+0.61 T q_{*}\right) / u_{*}^{2}
$$

The subscript $n$ denotes the value in neutral conditions (i.e., $\xi=0$ ) where $\psi=0$. For a reference height of $10 \mathrm{~m}$,
$C_{e n}$ and $C_{h n}$ are approximately $1 \times 10^{-3}$ and have little wind speed dependence [Liu et al., 1979; Smith, 1988]. The neutral transfer coefficients are related to the roughness lengths $\left(z_{o}\right.$ for velocity, $z_{o r}$ for temperature, and $z_{o q}$ for humidity), which are defined as the height where the extrapolation of the log- $z$ portion of the respective profile (of $u, T$, or $q$ ) intersects the surface value:

$$
\begin{aligned}
c_{T n}^{1 / 2} & =\frac{a \kappa}{\log \left(z_{r} / z_{o T}\right)} \\
c_{q n}^{1 / 2} & =\frac{a \kappa}{\log \left(z_{r} / z_{o q}\right)} \\
c_{d n}^{1 / 2} & =\frac{\kappa}{\log \left(z_{r} / z_{o}\right)}
\end{aligned}
$$

The scaling parameters from (1) can be computed independently from the transfer coefficients given in (6):

$$
\begin{aligned}
& T_{*}=-c_{T}^{1 / 2}\left(T_{s}-\theta\right) \\
& q_{*}=-c_{q}^{1 / 2}\left(q_{s}-q\right) \\
& u_{*}^{2}=C_{d} S u
\end{aligned}
$$

where $u$ denotes the magnitude of the mean wind vector (relative to the sea surface).

\subsection{Surface Characterization}

The velocity roughness length $z_{o}$ is often crudely related to the physical roughness of the surface [see Panofsky and Dutton, 1984, p. 123], but the scalar roughness lengths are more complicated. This is discussed in detail by Garratt [1992, chapters 4 and 5] or Kraus and Businger [1994, chapter 5], so only a brief background will be given here. From laboratory studies it has proven convenient to characterize the surface and the flow regime by the roughness Reynolds number,

$$
R_{r}=\frac{u \cdot z_{o}}{v}
$$

where $\mathbf{v}$ is the kinematic viscosity of air. For later use we also define the scalar equivalents of $R_{r}: R_{T}=\left(u_{*} z_{o T}\right) / v$ for temperature and $R_{q}=\left(u_{*} z_{o q}\right) / v$ for humidity. Figure 1 shows the relationship between $R_{r}$ and wind speed, obtained from Moana Wave data during COARE, which will be described in detail in section 5.2. According to these classical studies [e.g., Kraus and Businger, 1994], when $R_{r}<0.13$, the flow is said to be "aerodynamically smooth"; that is, the actual roughness elements on the surface are irrelevant and the surface stress is supported by viscous shear. As the wind speed decreases, $R_{r}$ approaches a constant value of about 0.11 and the relationship between roughness and stress is fixed:

$$
z_{o}=\frac{0.11 v}{u_{*}}
$$

For $R_{r}>2.0$ the flow is "rough" and the stress is dominated by pressure and viscous transfers associated with the roughness elements. 
Over the ocean, smooth flow occurs for 10-m wind speeds less than about $2 \mathrm{~m} \mathrm{~s}^{-1}$ and rough flow occurs for wind speed greater than about $8 \mathrm{~m} \mathrm{~s}^{-1}$. The roughness elements over the ocean are primarily surface gravity waves that are generated by the wind/stress. On the basis of scaling arguments about the slope of the average locally generated seas as a function of the surface stress, Charnock [1955] gave the mean relationship between oceanic roughness and stress for rough flow:

$$
z_{o}=\frac{\alpha u_{*}^{2}}{g}
$$

where $\alpha$ is the "Charnock" constant for which values between 0.010 and 0.035 can be found in the literature [e.g., Garratt, 1992, Table 4.1]. The value of the Charnock "constant" can be linked to gross characterizations of the sea state [Geernaert, 1990; Nordeng, 1991] such as the age or slope of the dominant wavelength (from the peak of the gravity wave spectrum). This has been used to explain, for example, the increase of the velocity transfer coefficient in shallow water. The literature on this subject is quite conflicting, so at this stage the subject must still be considered exploratory. Broader application also awaits the ready availability of wave spectral information. There have also been suggestions $[W u, 1968]$ that capillary waves contribute significantly to the stress at intermediate wind speeds. This implies that the surface tension of the surface of the ocean must be considered in wind/stress relationships. So far, clear experimental verification is sketchy.

For $10-\mathrm{m}$ wind speeds between 2 and $20 \mathrm{~m} \mathrm{~s}^{-1}$, decades of field programs have not succeeded in clearly demonstrating an open-ocean, neutral transfer coefficient for heat and moisture that is significantly different than $1.1 \times 10^{-3} \pm 15 \%$ [Garratt, 1992]. Despite this, the trend in characterizing heat and moisture transfer has been to follow laboratory and overland studies in parameterizing the scalar roughness lengths in terms of the roughness Reynolds number. The reasons are that the $15 \%$ uncertainty is no longer acceptable; also, considerations of the roughness structure give us an approach that can be extended to nonequilibrium wave states and can also be used to deal with air-sea transfer of trace gases. The leading examples are the model of Liu et al. [1979] (hereinafter referred to as LKB) and Brutsaert [1982].

In the laboratory, simple experiments have been done to determine the transfer of heat and moisture by molecular diffusive processes in the thin sublayer directly adjacent to the water surface. Brutsaert [1982] assumed that this nearsurface profile must match the log profile of turbulent transfer at some matching height. This leads to a relationship between the scalar roughness length (i.e., the log-profile variable) and the velocity roughness length that depends on $R_{r}$ (equation (10)). The LKB model is quite similar to that of Brutsaert, except the sublayer profile is given a specific (exponential) shape and the matching height is determined by equating the slopes of the two profile forms where they intersect. This difference, plus alternative choices of sublayer constants and specifications of the velocity behavior, leads to substantial differences between the two models with respect to the exchange coefficients used. Figure 2 illustrates this with the Moana Wave COARE measurements, which again will be described in detail in section 5.2.

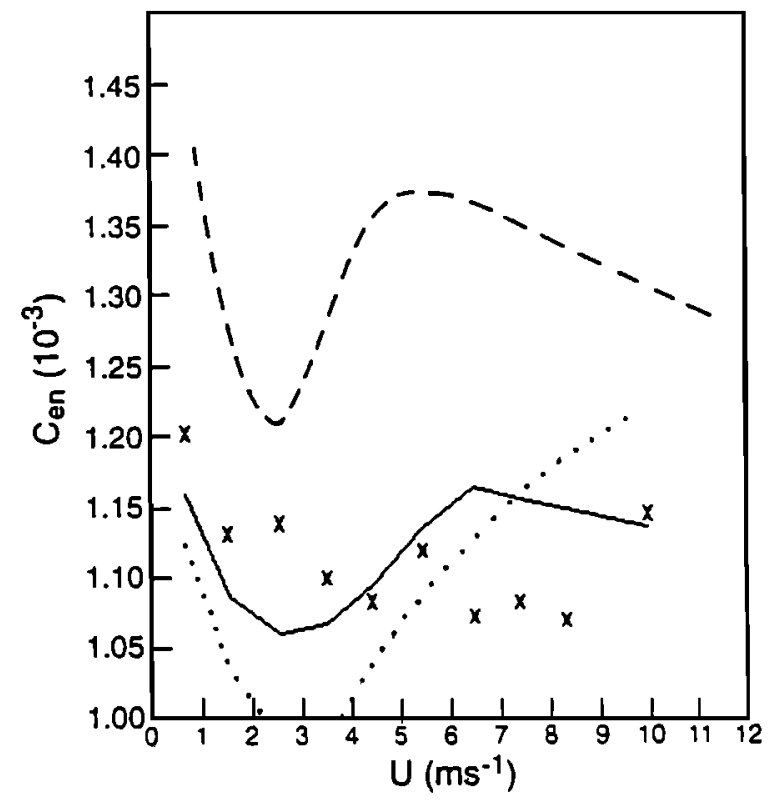

Figure 2. Neutral stability values for the $10-\mathrm{m}$ moisture transfer coefficient $C_{e n}$ as a function of $10-\mathrm{m}$ wind speed, bin averaged as in Figure 1 . The solid line is the COARE 2.0 model, the dotted line is the Garratt/Brutsaert model [Garratt, 1992; Brutsaert, 1982], and the dashed line is the original Liu-Katsaros-Businger (LKB) model [Liu et al., 1979] (see text). The crosses are derived from the Moana Wave covariance latent heat flux measurements.

\subsection{Convective Behavior}

Within the framework of MOS many dynamical variables have clearly defined asymptotic behavior in the so-called free convection limit [Panofsky and Dutton, 1984; Garratt, 1992], when $u_{*}$ approaches zero but the buoyancy flux does not (that is, $L$ goes to zero). For example, the dimensionless vertical gradients of scalar quantities are expected to exhibit a $\xi^{-1 / 3}$ dependence. This leads to a scalar profile function of the form

$$
\psi_{c}=1.5 \ln \left[\frac{y^{2}+y+1}{3}\right]-\sqrt{3} \arctan \left[\frac{2 y+1}{\sqrt{3}}\right]+\frac{\pi}{\sqrt{3}}
$$

where

$$
y=\sqrt[3]{1-\gamma \xi}
$$

and $\gamma$ is an empirical constant. Note that the convective limit argument says nothing about the form of these functions near neutral stability. Numerous overland field programs have determined the forms of the profile functions for near-neutral conditions [Hogstrom, 1988], but the experimental difficulties of measuring the small gradients in the convective limit have prevented clear verification of (13).

It is clear, however, that expressions such as (6) may become singular if $\psi$ becomes too large. Furthermore, Godfrey and Beljaars [1991] have pointed out that (6) cannot be applied in the strict convective limit because it is based on the constraint that the magnitude of $z_{o q} / L \ll 1$. This has 
resulted in attempts to sidestep the MOS framework and scale the problem directly (see Liu [1989] for a discussion). Laboratory studies have indicated that sensible heat flux does scale as the $4 / 3$ power of the air-sea temperature difference. These studies use scaling arguments that depend on the molecular diffusivities. These concepts have been generalized and applied in a limited way to the ocean [Golitsyn and Grachev, 1986]. Following an approach based on boundary layer convective similarity, Stull [1994] has developed a scaling model where the sensible heat flux scales as the $3 / 2$ power of temperature difference and the $1 / 2$ power of the depth of the convective boundary layer $z_{I}$. Note that Stull's theory was originally for smooth flow, where the actual physical roughness of the surface is no longer relevant (that is, $z_{I}$ is the length scale), but he has suggested that it is also valid for rough flow.

Another approach has been developed by noting that in (2) the parameter $S$ is, in fact, the average value of the wind speed, not the magnitude of the mean wind vector. Schumann [1988] and Godfrey and Beljaars [1991] expressed $S$ as

$$
S^{2}=u_{x}^{2}+u_{y}^{2}+w_{g}^{2}=u^{2}+w_{g}^{2}
$$

where $u_{x}$ and $u_{y}$ are the mean wind components, $w_{g}$ is proportional to the convective scaling velocity

$$
w_{g}=\beta W_{*}
$$

and $\beta$ is an empirical constant, of the order of 1.0 , but which depends on the temporal/spatial scale used to compute the averages. We compute $W_{*}$ as follows:

$$
W^{3}=\frac{g}{T}\left[\frac{H_{s}}{\rho_{a} c_{p a}}+0.61 T \frac{H_{l}}{\rho_{a} L_{e}}\right] z_{i}
$$

Algebra shows that as the mean vector wind approaches zero, $S$ will approach $\beta W$ * and (2) will yield a result equivalent to Stull's [1994] scaling theory.

Sykes et al. [1993] carried this concept further by examining the structure of the local profiles within the gusts. Whereas (2c) properly implies that the average stress vector approaches zero as the average vector wind approaches zero, the local turbulence intensity that drives the scalar fluxes and determines the local roughness length within the gusts must be scaled by the wind speed:

$$
u_{* t}^{2}=C_{d} S^{2}
$$

The point is if the wind blows at $1 \mathrm{~m} \mathrm{~s}^{-1}$ from the east for half an hour and then blows at $1 \mathrm{~m} \mathrm{~s}^{-1}$ from the west for half an hour, it is the average wind speed of $1 \mathrm{~m} \mathrm{~s}^{-1}$ that must be used to compute roughness Reynolds number, the scalar transfer coefficients, and the MOS stability parameters.

\subsection{Flux/Moisture Corrections}

The flux accuracy guidelines set by the COARE working groups have placed unprecedented demands on measurements and computation. We no longer have the luxury of being able to use "ballpark" figures for geophysical parameters such as the acceleration of gravity, the latent heat of vaporization of water, the vapor pressure of pure water (as opposed to seawater), etc. Businger [1982] discussed at length the issue of the additional contributions to the heat carried by. atmospheric moisture. He showed that the total enthalpy transported by turbulent correlations is

$$
\begin{aligned}
\overline{\rho_{a} w h}= & \rho_{a} \overline{w^{\prime} T^{\prime}}\left[c_{p a}+q\left(c_{p v}-c_{p a}\right)\right] \\
& +\rho_{a} \overline{w^{\prime} q^{\prime}}\left[c_{p v}\left(T-T_{r}\right)+L_{e}\right]
\end{aligned}
$$

where $\rho_{a}$ is the density of moist air, $c_{p a}$ is the specific heat of dry air, $c_{p v}$ is the specific heat of water vapor, and $T_{r}$ is a reference temperature. This development follows Frank and Emmitt [1981] and corrects an erroneous expression developed by Brook [1978]. Businger [1982] pointed out that the proper reference temperature in this application is the SST, $T_{s}$. The second $c_{p v}$ term represents the heat required to cool the water vapor from $T_{s}$ to the air temperature after it is evaporated. Thus the total sensible heat is

$$
\begin{aligned}
H_{s}= & \rho c_{p a}\left\{\overline{w^{\prime} T^{\prime}}\left[1+q\left(c_{p v}-c_{p a}\right) / c_{p a}\right]\right. \\
& \left.+\overline{w^{\prime} q^{\prime}}\left(T-T_{s}\right) c_{p v} / c_{p a}\right\}
\end{aligned}
$$

For TOGA COARE both of these correction terms are, on average, less than $0.2 \mathrm{~W} \mathrm{~m}^{-2}$ and of opposite sign. Because it is unlikely that bulk fluxes will approach this accuracy, even in an average sense, in the near future we suggest that these correction terms be neglected.

A second issue is the proper lower boundary condition for the total mass flux, as discussed by Webb et al. [1980], which has become known as the "Webb effect." Webb et al. [1980, p. 87] described the problem,

If the heat flux is upwards (positive) then rising air parcels are on average warmer than descending parcels, so that on the assumption of zero mean vertical mass flow of air there must exist a small mean upward velocity component. Thus, in measurements which include the fluctuations of density (of a minor constituent) and of vertical airspeed, $w$, about its mean $\bar{w}$, the contribution to the flux of (the constituent) associated with $\bar{w}$ is missed, and an appropriate correction having the same sign as the heat flux must be added.

This small mean vertical velocity is given by

$$
\bar{w}=1.61 \overline{w^{\prime} q^{\prime}}+(1+1.61 q) \overline{w^{\prime} T^{\prime}} / T
$$

This leads to a correction that must be added to the latent heat flux:

$$
H_{l W}=\rho_{a} L_{e} \bar{w} q
$$

For the COARE observation period, $H_{l \mathrm{w}}$ has an average value of $4 \mathrm{~W} \mathrm{~m}^{-2}$.

\subsection{Precipitation Effects}

Gosnell et al. [1995] showed that the sensible heat transferred to the ocean surface by the rain can be represented as

$$
H_{s r}=-R c_{p w} \alpha_{w}\left(1+B_{o}^{-1}\right) \Delta T
$$

where $R$ is the rain rate (liquid water flux), $c_{p w}$ is the specific 
heat of liquid water, $\alpha_{w}$ is the Clausius-Claperyon wet-bulb factor [Fairall et al., 1994], $B_{o}$ is the bulk Bowen ratio, and $\Delta T$ is the sea-air temperature difference. This equation assumes that the rain is at the wet-bulb temperature. Assuming a sea-air temperature difference of $2^{\circ} \mathrm{C}$, the mean rainfall for the COARE intensive observing period (IOP) of $10 \mathrm{~mm} \mathrm{~d}^{-1}$ gives a heat flux of $2.5 \mathrm{~W} \mathrm{~m}^{-2}$. Climatologically, this is less than our error in the total heat budget of the warm pool, although in a given 1-hour period it can be 30 times larger. We include it as part of our consideration of the bulk flux algorithm because it can be written in terms of simple bulk variables.

The stress imparted to the ocean surface by rainfall has been considered by Caldwell and Elliott [1971], who showed that substantial increases in the effective drag coefficient could result from this effect. A rough numerical estimate of the momentum of rainfall is given by the product of rain mass flux and wind velocity (at, say, $10 \mathrm{~m}$ height, not the surface wind); $\tau_{r}=R u / 3600$, where $R$ is the rain rate in millimeters per hour and water density is implicit. The direct wind stress follows from (1) and (2c) as $\tau_{w}=\rho_{a} C_{d} u^{2}$, when taking $C_{d}=0.0013$, we have $\tau_{r} / \tau_{w}=0.18 R / u$, both stresses acting in the wind direction. Rain rates of $100 \mathrm{~mm} \mathrm{~h}^{-1}$ lasting several minutes, with storm winds of $10 \mathrm{~m} \mathrm{~s}^{-1}$, were not uncommon during COARE, in which case the stress due to rainfall is almost double that directly due to the wind. COARE-averaged values of $u$ and $R$ measured by the Moana Wave were about $5 \mathrm{~m} \mathrm{~s}^{-1}$ and $0.5 \mathrm{~mm} \mathrm{~h}^{-1}$, respectively, so that overall, this is a $2 \%$ effect. At this stage, rain momentum is not incorporated in the bulk code, but clearly, it can be important on short timescales.

\section{Measurement Issues}

Details on the Moana Wave instruments and various data processing techniques have been provided elsewhere [Fairall et al., 1990; Fairall and Young, 1991; Edson et al., 1991; Hare et al., 1992; Young et al., 1992; Chertock et al., 1993; Fairall and White, 1994; Young et al., 1995]. Also, a complete description of the various intercomparisons, instrument calibration, and correction procedures for the COARE flux platforms is given by E. F. Bradley et al. (Ship-based air-sea flux measurements during TOGA COARE, submitted to Journal of Atmospheric and Oceanic Technology, 1995) (hereinafter referred to as a submitted manuscript).

\subsection{Flux Measurements}

The general issue of direct covariance flux measurements is well documented and needs no further discussion here [e.g., Panofsky and Dutton, 1984; Businger, 1986; Wyngaard, 1990]. Such measurements from ships involve additional complications caused by ship motions, flow distortion, and the contaminating effects of the marine environment. Techniques to correct anemometer velocities for ship motion are derived from earlier aircraft work, with most of the effort being directed toward developing a motion system that does not cost more than the meteorological system. Early efforts in this realm were made by Fujitani [1985], but now, several investigators have reported success [e.g., Tsukamoto et al., 1990; Hare et al., 1992]. To date, only Hare [1992] has carefully examined the correction equations (this involved the computation of 300 third-order covariance terms) to determine the sources of motion error in stress measurements and to devise an instrument location strategy to minimize them. Oost et al. [1993] examined the flow distortion effects of both large structures (e.g., a platform or a ship's superstructure) and small objects near the anemometer (such as mounting brackets or other instruments). Unfortunately, there is no theory to describe the first type of distortion effect, and wind tunnel simulations, which worked nicely for the mean flow distortion, failed to give credible results for the fluxes. Thus empirical methods such as intercomparisons with other measurement platforms (presumably, with no or at least much less distortion) or flux estimation methods are necessary. Naturally, the minimization of motion errors and the minimization of flow distortion are mutually exclusive. Combating the marine environment requires careful selection of robust instruments, extremely attentive monitoring of sensor performance, and frequent cleaning [Fairall et al., 1990; Edson et al., 1991; Larsen et al., 1993]. Clearly, shipship, ship-buoy, and ship-aircraft intercomparisons are essential to establish the credibility and accuracy of the ship flux measurements. However, the reader is wamed that the flux measurements used here (particularly covariance stress measurements) are still not perfect (see discussion in section 5.3).

\subsection{Bulk Measurements}

The TOGA COARE goal of no more than $10 \mathrm{~W} \mathrm{~m}^{-2}$ uncertainty in the total surface energy budget of the ocean (including turbulent, radiative, and precipitation heat fluxes) implies certain accuracy requirements for the bulk measurements. Partitioning the error equally between the net radiative components and the turbulent components (neglecting the uncertainty in the precipitation component) and assuming that these errors are independent suggests an allowable uncertainty in $\left(H_{l}+H_{s}\right)$ of about $6-7 \mathrm{~W} \mathrm{~m}^{-2}$. Assuming that the average uncertainty in the empirical transfer coefficients can be made arbitrarily small, then the uncertainty in the bulk heat fluxes computed via (2) can be approximated (see Blanc [1986, 1987] for detailed analyses):

$$
\frac{\delta F_{x}}{F_{x}}=\delta S / S+\frac{\left(\delta X_{s}-\delta X\right)}{\left(X_{s}-X\right)}
$$

This leads to the following combined limits on the systematic errors in the mean variables [Fairall and McPhaden, 1993]:

$$
\begin{aligned}
& \delta S=\delta u=0.2 \mathrm{~m} \mathrm{~s}^{-1} \\
& \delta T_{s}=0.2 \mathrm{~K} \\
& \delta T=0.2 \mathrm{~K} \\
& \delta q=0.2 \mathrm{~g} \mathrm{~kg}^{-1}
\end{aligned}
$$

These are one half to one third of the uncertainties suggested by Blanc [1986] for measurements on weather ships. Typical claimed accuracies for commercial humidity sensors are $3 \%$. Because the sea-air humidity difference in the COARE region is about $1 / 3$ the mean humidity, this translates into an uncertainty in the derived transfer coefficient of about $10 \%$, not including average errors in the determination of the humidity flux or the SST. Remember that we can reduce the contribution of random errors by averaging, but not systematic errors. To meet the COARE goal of a 
Table 1. TOGA COARE R/V Moana Wave Measurement Accuracies

\begin{tabular}{llccc}
\hline \multicolumn{1}{c}{ Variable } & \multicolumn{1}{c}{ Definition } & Units & 50-min rms & Bias \\
\hline$u$ & wind & $\mathrm{m} \mathrm{s}^{-1}$ & 0.3 & \pm 0.2 \\
$T$, day & air temperature & $\mathbf{K}$ & 0.3 & \pm 0.2 \\
$T$, night & air temperature & $\mathbf{K}$ & 0.2 & \pm 0.1 \\
$q$ & specific humidity & $\mathrm{g} \mathrm{kg}^{-1}$ & 0.3 & \pm 0.2 \\
$T_{s}$ & sea surface temperature & $\mathrm{K}$ & 0.1 & \pm 0.2 \\
$q_{s}$ & saturation $q$ at $T=T_{s}$ & $\mathrm{~g} \mathrm{~kg}^{-1}$ & 0.1 & \pm 0.2 \\
$H_{s}$, cov & sensible heat flux & $\mathrm{W} \mathrm{m}^{-2}$ & $3 \pm 20 \%$ & \pm 2 \\
$H_{l}$, cov & latent heat flux & $\mathrm{W} \mathrm{m}^{-2}$ & $5 \pm 20 \%$ & \pm 4 \\
$\tau$, cov & stress & $\mathrm{N} \mathrm{m}^{-2}$ & $0.015 \pm 30 \%$ & 0.002 \\
$|\tau|$, ID & stress & $\mathrm{N} \mathrm{m}^{-2}$ & $15 \%$ & 0.002 \\
$R_{s}$ & downward solar flux & $\mathrm{W} \mathrm{m}^{-2}$ & $1 \%$ & \pm 4 \\
$R_{l}$ & downward longwave flux & $\mathrm{W} \mathrm{m}^{-2}$ & 5 & \pm 2.5 \\
$R$ & precipitation & $\mathrm{mm} \mathrm{h}^{-1}$ & $15 \%$ & $15 \%$ \\
\hline
\end{tabular}

Values are estimated. Bias is average sensor minus average corect value. Here cov refers to estimates computed using the covariance flux technique; ID refers to the inertial dissipation technique. Data are based on Bradley et al. (submitted manuscript, 1995).

$10 \mathrm{~W} \mathrm{~m}^{-2}$ uncertainty in the heat balance of the warm pool, unprecedented accuracies must be obtained in fluxes and mean meteorological variables. This requires examination of sensor calibrations, fast sensor response, flow distortion and ship influence, and processing methods. To accomplish this, we developed a program of postcalibrations and analysis of side-by-side field data with other ships, buoys, and aircraft. Details are given by Bradley et al. (submitted manuscript, 1995); estimates of measurement accuracies are given in Table 1.

\subsection{Sea Surface Temperature}

Sea surface temperature presents special problems in bulk flux applications because of the variety of measurement methods. Strictly speaking, the temperature required in (2) is the interfacial temperature of the water that is in direct contact with the atmosphere. Because the sensible, latent, and longwave radiative fluxes are realized in the upper fractions of a millimeter of the surface, they lead to a "cool skin," which has been long recognized [Woodcock, 1941; Saunders, 1967]. Thus the interface is about $0.2-0.5 \mathrm{~K}$ cooler than the water a millimeter below the surface. Typical bulk thermometers placed in the water to make contact temperature measurements are usually unable to resolve this thin layer, and their readings characterize the bulk temperature below the cool skin. A properly calibrated and corrected radiative thermometer can measure the actual interface temperature unambiguously [e.g., Schluessel et al., 1990; Coppin et al., 1991; Emery et al., 1994]. About half the solar radiation is absorbed in the upper meter of the ocean, so there are substantial diurnal variations in the water temperature profile in the upper few meters. The details of the profile are determined by the solar absorption characteristics of the water and the convective and wind-driven turbulence in the ocean's mixed layer. In light winds the surface temperature can warm by several degrees and this diurnal warm layer may be less than a meter deep [e.g., Price et al., 1986]; with increasing wind speed the surface warming gets mixed down and its effect may become negligible on the computed bulk fluxes.
Clearly, radiative SST sensors do not require corrections for cool-skin and diumal warm-layer effects, but bulk sensors do. We have incorporated into the COARE 2.0 algorithm corrections for both effects. The details are described by Fairall et al. [1996]. The cool-skin and warm-layer algorithms require additional data input of solar and IR radiative fluxes. The warm-layer algorithm requires specification of the sensor depth. The correction is based on integrals of the surface energy and momentum budgets [Price et al., 1986], so a reasonably complete time series is required (i.e., it cannot be applied to a single measurement by itself).

\section{Flux Estimation Algorithm}

\subsection{Description}

The COARE 2.0 bulk flux algorithm is presently structured in terms of roughness Reynolds number following the approach of LKB. On the basis of data from recent measurement programs, including COARE, we have adjusted some of the empirical constants and added additional physics, as described in sections 2 and 3 . The specifics are as follows:

1. Combining the formulas of LKB and Charnock [1955] (equations (11) and (12)) for the roughness length, we obtain

$$
z_{o}=\alpha \frac{u_{*}^{2}}{g}+0.11 \frac{v}{u_{*}}
$$

as suggested by Smith [1988].

2. Altering the dependence on stability of the profiles of temperature, moisture, and momentum in highly unstable conditions, $\xi=z_{r} / L \ll-1$. To do this, we begin with profile functions that obey the $\xi^{-1 / 3}$ asymptotic convective limit dependence on stability, as discussed in section 2.3. This form is blended with the standard Kansas-type [Businger et al., 1971] functions $\left(\psi_{T K}\right.$ and $\left.\psi_{u K}\right)$ in the following manner:

$$
\Psi_{x}=\frac{1}{1+\xi^{2}} \Psi_{x K}+\frac{\xi^{2}}{1+\xi^{2}} \Psi_{c}
$$


3. Following Godfrey and Beljaars [1991], we use a gustiness velocity $w_{g}$ in the computation of the mean wind speed, as in (15) and (16). For the calculation of $W_{*}$ in (17), we have used $z_{I}=600 \mathrm{~m}$ based on ceilometer and aircraft measurements of the typical boundary layer cloud-base height for COARE. A value of $\beta$ of 1.25 was determined from the Moana Wave measurements of horizontal velocity variance (that is, $\beta^{2}=\left(\sigma_{u}^{2}+\sigma_{v}^{2}\right) / W_{*}^{2}$ ) at 50 -min timescales.

4. Cool-skin and warm-layer corrections for nonradiative SST measurements, as discussed in section 3.3, are incorporated into the algorithm.

5. The "Webb" correction [Webb et al., 1980] to the heat flux is computed as in (22) and the precipitation heat flux is computed as in (23).

\subsection{Implementation}

The algorithm is presently structured to process data from a given platform with a particular instrument configuration that is operating in a single time zone on 1-day timescales. The main program consists of several modules to compute specific variables.

Step 1. The platform inputs are as follows: input atmospheric measurement heights and water temperature sensor depth; input inversion height, surface pressure, and approximate latitude of measurements; and set all predetermined constants (von Kármán, etc.). The following three steps refer to the main loop.

Step 2. A line of data from time series is input as follows: local time, $u, T_{s}, T, q, R, R_{l l}, R_{s !}$; and correct $T_{s}$ and $q_{s}$ for warm layer from the previous main loop step (warm layer set to zero at local midnight).

Step 3. Assign $w_{g}=0.5 \mathrm{~m} \mathrm{~s}^{-1}$ and neutral stability transfer coefficients as a first guess and compute $u_{* t}, T_{*}$, and $q_{*}$ as follows: compute all temperature-dependent constants; and set loop count to zero.

Step 4. Stability iteration is as follows: compute $\xi$ (from (7)); compute $z_{o}$ (from (25)); compute $R_{r}$ (from (10)); compute $R_{q}$ and $R_{T}$ (LKB formula and Figure 3); compute $z_{o q}$ and $z_{o T}$; and compute neutral transfer coefficients (from (8)).

The following steps invoke the crucial stability dependence: compute $\psi$ functions (from (13) and (26)); compute stability-dependent transfer coefficients using (6); compute $u_{* t}$ (from (18)), $q_{*}$, and $T_{*}$ (from (9)); compute fluxes (from (1)); compute $W$. (from (17)); if unstable, compute $w_{g}$ (from (16)) (otherwise, $w_{g}=0.0$ ); compute coolskin correction to $T_{s}$ and $q_{s}$; increment loop count; and if loop count $<20$, then go to step 4 .

Note that the process normally converges within five iterations. For extremely stable conditions it will not converge, and zero fluxes result.

Step 5. The final computations are as follows: compute Webb and precipitation fluxes; increment integrals for warm layer; and compute $u$, and stress. The final step, step 6 , is to go to the main loop.

\subsection{Choice of Constants}

The following constants are used in the COARE 2.0 version: Chamock $\alpha=0.011$; convection $\beta=1.25$; convective profile $\gamma=12.87$; von Kármán $\kappa=0.40$; scalar correction $a=1.00$; gravity $g=9.72 \mathrm{~m} \mathrm{~s}^{-2}$; inversion height
$z_{I}=600 \mathrm{~m}$; mean ocean albedo $=0.055$; and mean ocean emissivity $\varepsilon=0.97$. Also, $L_{e}$ [Fleagle and Businger, 1980, p. 113] and $v$ [Andreas, 1989, p. 31] are given well-known temperature dependent forms.

\section{COARE Analysis}

\subsection{Background}

The COARE bulk algorithm began evolving with the COARE pilot cruise in 1990 [Young et al., 1992] and continued with a number of pre-COARE cruises by Australian and U.S. research groups. This early work provided valuable insights on some mean sensor calibration problems and uncovered several false steps in the ship motion removal problem. A post-COARE deployment of the R/P FLIP off California [Fairall and Edson, 1994] proved invaluable in sorting out some of the small inconsistencies in the Environmental Technology Laboratory system (Bradley et al., submitted manuscript, 1995) provides further discussion). The results we present here will emphasize the measurements made on the R/V Moana Wave during COARE. This is because the Moana Wave fluxes were computed in real time and were available for algorithm evaluation as soon as COARE ended. Thus in terms of the total COARE database from all platforms, the results we present here must be considered preliminary. It is also important to realize that the Moana Wave operated primarily in a "drift" mode while deploying ocean microstructure instruments, and in light winds the relative ventilation of the ship's atmospheric sensors was quite weak. Light and variable winds may lead to contamination by the ship's structure and heat island effects. Also, light relative winds greatly increase the sampling uncertainty, a particular problem for covariance fluxes [Wyngaard, 1990]. These effects, plus extreme sensitivity to imperfections in the ship motion corrections, lead to the large uncertainty in 50-min covariance stress measurements, noted in Table 1 . Since several of the flux-measuring ships in COARE took data while under way, more definitive information on this issue will soon be available.

The Moana Wave operated in the COARE intensive flux array for three cruise legs between November 1992 and February 1993. Except for two stops at the equator (at the start of leg 2 and the end of leg 3), the ship was stationed within $10 \mathrm{~km}$ of the Woods Hole Oceanographic Institution's integrated meteorological (IMET) buoy nominally located at $2^{\circ} \mathrm{S}$ latitude and $156^{\circ} \mathrm{W}$ longitude. A summary of the measurements for each leg and the average of all three are presented in Table 2. Note that the values for the turbulent fluxes used to compute these averages are taken from the covariance measurements unless they were deemed compromised by experimental conditions that interfered with the instruments or otherwise invalidated the results. Conditions that were considered included precipitation, unfavorable relative wind direction, Sun or salt contamination of the fast humidity sensor, excessive flow tilt, and ship maneuvers. If the covariance measurement for a particular sample period was deemed invalid, the bulk value was substituted for computing the cruise average. Also, invalid periods were not used in the bulk-turbulence comparisons discussed later in this section.

The summary presented in Table 2 indicates that the November to early December period was characterized by 
Table 2. Data Summary From the Moana Wave During COARE

\begin{tabular}{|c|c|c|c|c|}
\hline Variable & Leg 1 & Leg 2 & Leg 3 & Total \\
\hline Dates & Nov. 11-Dec. 3 & Dec. 16-Jan. 11 & Jan. 28-Feb. 16 & Nov. $11-F e b .16$ \\
\hline $\begin{array}{l}\text { Number of } 50-\min \\
\text { observations }\end{array}$ & 589 & 648 & 385 & 1622 \\
\hline$u, \mathrm{~m} \mathrm{~s}^{-1}$ & 3.40 & 5.49 & 4.77 & 4.56 \\
\hline$T_{s},{ }^{\circ} \mathrm{C}$ & 29.45 & 28.98 & 29.11 & 29.18 \\
\hline$T,{ }^{\circ} \mathrm{C}$ & 27.96 & 27.38 & 27.56 & 27.63 \\
\hline$q, \mathrm{~g} \mathrm{~kg}^{-1}$ & 18.06 & 18.08 & 18.06 & 18.07 \\
\hline$q_{s}, \mathrm{~g} \mathrm{~kg}^{-1}$ & 25.23 & 24.53 & 24.72 & 24.83 \\
\hline$H_{s}, \mathrm{~W} \mathrm{~m}^{-2}$ & 6.6 & 10.9 & 9.6 & 9.1 \\
\hline$H_{1}, \mathrm{~W} \mathrm{~m}^{-2}$ & 88.1 & 113.1 & 109.0 & 103.5 \\
\hline$H_{l W}, \mathrm{~W} \mathrm{~m}^{-2}$ & 3.2 & 4.3 & 4.1 & 3.9 \\
\hline$H_{\mathrm{ran}}, \mathrm{W} \mathrm{m}^{-2}$ & 0.9 & 3.8 & 2.6 & 2.5 \\
\hline$R_{s 1}, \mathrm{~W} \mathrm{~m}^{-2}$ & 235.4 & 176.3 & 200.9 & 203.6 \\
\hline$R_{\mu}, \mathrm{W} \mathrm{m}^{-2}$ & 408.3 & 417.5 & 412.6 & 413.0 \\
\hline$R_{\text {net }}, \mathrm{W} \mathrm{m}^{-2}$ & 160.9 & 115.9 & 134.0 & 136.5 \\
\hline$R_{\text {net }}-H_{l}-H_{s}$ & 66.2 & -8.1 & 15.4 & 24.3 \\
\hline$H_{\text {tol }}, \mathrm{W} \mathrm{m}^{-2}$ & 62.1 & -27.4 & 8.7 & 17.9 \\
\hline Rain, mm d & 4.0 & 18.5 & 11.8 & 11.6 \\
\hline$\tau, \mathrm{N} \mathrm{m}^{-2}$ & 0.030 & 0.055 & 0.040 & 0.040 \\
\hline$u^{2}, \mathrm{~m}^{2} \mathrm{~s}^{-2}$ & 14.8 & 40.7 & 27.1 & 28.1 \\
\hline
\end{tabular}

See Table 1 for definitions. $H_{l w}$ is Webb et al.'s [1980] contribution to latent heat flux; $H_{\text {rain }}$ is rain thermal contribution to sensible heat flux; $R_{\text {net }}$ is the net radiation; $H_{\text {tot }}$ is the total heat flux to the ocean; and $u^{2}$ is the mean of the square of the wind speed.

light winds, little precipitation, and clear skies; the later December through January period, by stronger winds, heavy precipitation, and cloudy skies; the February period was typical of the overall average. Also, the grand average of the total heat input to the ocean was $17.9 \mathrm{~W} \mathrm{~m}^{-2}$; this includes a $6.4 \mathrm{~W} \mathrm{~m}^{-2}$ contribution from the combined effects of cooling by precipitation and the Webb correction [Webb et al., 1980]. The total heating/cooling rates for the individual legs are approximately consistent with the changes in the SST observed.

\subsection{Bulk Algorithm Evaluation}

Because in COARE we have direct measurements of the turbulent fluxes, $u_{*}, q_{*}$, and $T_{*}$, through covariance and inertial dissipation techniques, we are able to evaluate a number of assumptions and parameters used in calculating the bulk algorithm. For this purpose, we averaged the Moana Wave data (fluxes and mean observables) and bulkderived variables into mean wind speed bins with $1 \mathrm{~m} \mathrm{~s}^{-1}$ bin widths.

Reliable and stable values of the stress $u_{*+}^{2}$ are central to much of this analysis. Referring ahead to comparisons of the flux data, we see that the covariance values of stress are, as is usual at sea, the noisiest and most sensitive to ship motion contamination (Figure 9b). The inertial dissipation values (Figure 9a) are much less scattered, so we use these in our initial evaluation, namely, the behavior of $R_{r}$ in the bulk algorithm. For this, we use the direct flux estimates to compute $z / L$ via (7); (6) can then be solved for $c_{d n}^{1 / 2}$, when we obtain $z_{o}$ by inverting (8). Direct measurement and the bulk algorithm (via (25)) thus yield independent values for $u_{*}$ and $z_{o}$ that are used to compute the roughness Reynolds number, shown as a function of wind speed in Figure 1, with good agreement.
This and the comparison of Figure 9, we believe, constitute satisfactory validation of the stress and velocity aspects of the bulk algorithm. For the subsequent examination of the scalar quantities therefore, we will adopt bulk-derived values of $R_{r}, u_{* t}$, and $c_{d n}^{1 / 2}$ for the additional smoothing that they offer. First, we use covariance measurements of latent heat flux to directly estimate the neutral transfer coefficient and roughness Reynolds number $R_{q}$ for moisture. Note that this involves the following steps: (1.) Using the average bulk-derived values of $u_{* t}^{2}$ (to account for gustiness), $q_{*}$ is computed from the mean of covariance and inertial-dissipation values of $H_{l}$ via (1). (2.) Using $q$. and the sea-air humidity difference, $c_{q}^{1 / 2}$ is computed via (9). (3.) Using $u_{*_{f}}$ and the mean covariance sensible heat flux, $\xi$ is computed via (7). (4.) Using this value for $\xi$, (6) is inverted to compute $c_{q n}^{1 / 2}$. (5.) Using $c_{q n}^{1 / 2}, z_{o q}$ is computed via (8). Using $z_{o q}$, the $10-\mathrm{m}$ reference height value for $c_{q n}^{1 / 2}$ is computed. (6.) $R_{q}$ is computed via (10). (7.) The $10-\mathrm{m}$ neutral transfer coefficient $C_{e n}$ is computed as $c_{d n}^{1 / 2} \times c_{q n}^{1 / 2}$.

Because the velocity parameter is essentially "taken out" in step 1 and then "put back in" in step 7, it has virtually no effect of the final value of $C_{e n}$. Thus the result is not actually dependent on whether we use bulk-derived or directly measured turbulence parameters in the analysis, but this method does affect the values of $R_{q}$. We chose this approach to alleviate the highly noisy velocity turbulence measurements at low wind speeds, and we are comfortable with (25) as a representation of the mean roughness of the ocean during COARE. The bin-averaged results for $C_{e n}$ are shown in Figure 2, along with curves from the original LKB model and the Garratt/Brutsaert model [Garratt, 1992; Brutsaert, 1982] (neither model has been tuned to the COARE data). The solid curve in Figure 2 is the present form of the COARE 2.0 algorithm, which agrees fairly well 


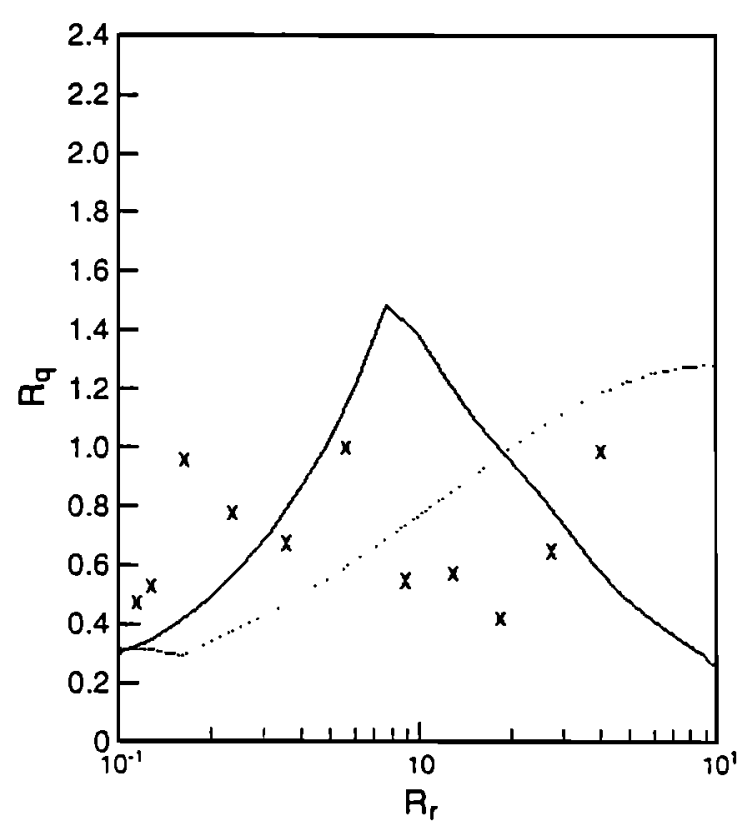

Figure 3. Moisture roughness Reynolds number $R_{q}$ versus $R_{r}$ derived from the fluxes averaged in wind speed bins as in Figure 1. The solid line is the COARE 2.0 model (same as the original LKB model), and the dotted line is the Garratt/ Brutsaert model (see text). The crosses are derived from the Moana Wave covariance latent heat flux measurements.

with the direct measurements (note the very expanded scale of the ordinate).

Figure 3 shows $R_{q}$ as a function of $R_{r}$ from this same analysis. This comparison looks quite different because the effects of the different $z_{o}$ parameterizations used in the three

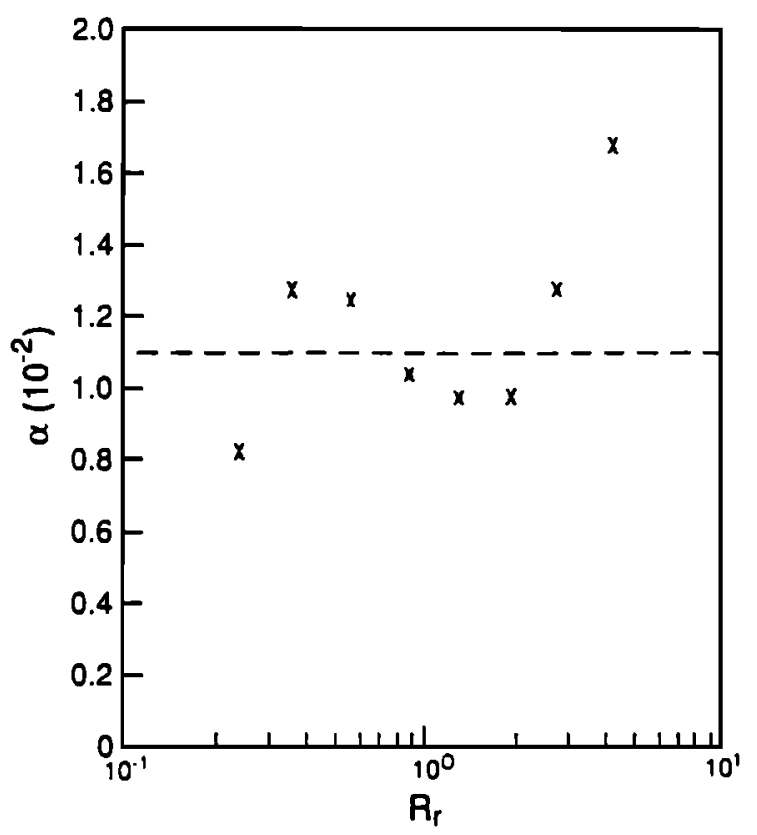

Figure 4. Charnock [1955] constant $\alpha$ versus $R_{r}$ derived from the fluxes averaged in wind speed bins as in Figure 1. The dashed line is the value of 0.011 used in the COARE 2.0 model, and the crosses are derived from the Moana Wave inertial-dissipation stress measurements. models shown in Figure 2 are removed. Note also that the small statistical scatter $( \pm 0.03)$ in the neutral transfer coefficient leads to rather large scatter in $R_{q}$. After much deliberation we decided not to adjust the LKB parameterization of $R_{q}$ to fit these measurements. This issue will be revisited when data from other flux measuring platforms become available.

The bin-averaged data have also been used to estimate the Charnock constant. Here we simply take inertial-dissipation values of $u_{*}$ to compute $z_{o}$ in the manner described above. Using (25), we can then compute a value for $\alpha$ for each bin. These data are shown as functions of $R_{r}$ in Figure 4 and are consistent with the value of 0.011 we use in the bulk code. In a similar fashion we have taken bin-averaged values of the sum of the horizontal wind component variances, as described in point 3 of section 4.1, and computed $W^{2}$. from (17) using the bin average of the buoyancy flux. The square root of the ratio of these two variables yields an estimate of $\beta$ for the 50-min timescale, as shown in Figure 5. In the low wind speed (small $R_{r}$ ) regime the value is consistently very close to 1.25 . It increases slightly with wind speed outside the convective regime, but there the gustiness effect is negligible, so a slight underestimate of $\beta$ will be unimportant.

Before going on to the flux intercomparisons, it is of interest to ponder the relative importance of the processes we have attempted to represent with this approach. To do this, we write the latent heat flux in the following form:

$$
H_{l}=\rho_{a} L_{e}\left[C_{e n} u\left(q_{s}-q\right)\right] \times \text { stability } \times \text { gustiness }
$$

where

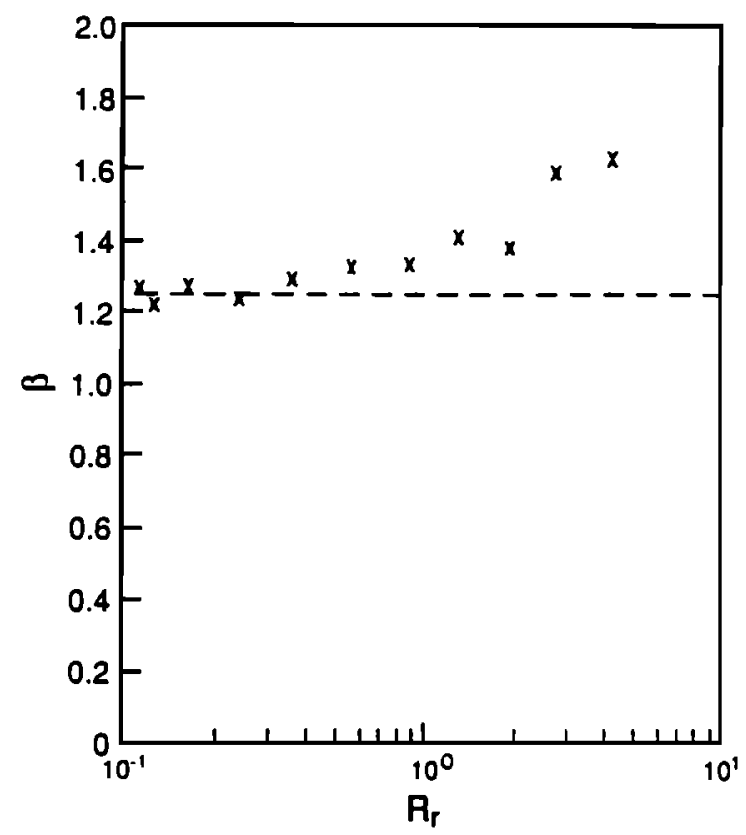

Figure 5. Gustiness constant $\beta$ versus $R_{r}$ derived from the horizontal velocity variances and the sensible heat flux (used to compute convective scaling velocity) averaged in wind speed bins as in Figure 1. The dashed line is the value of 1.25 used in the COARE 2.0 model, and the crosses are derived from the Moana Wave measurements. 

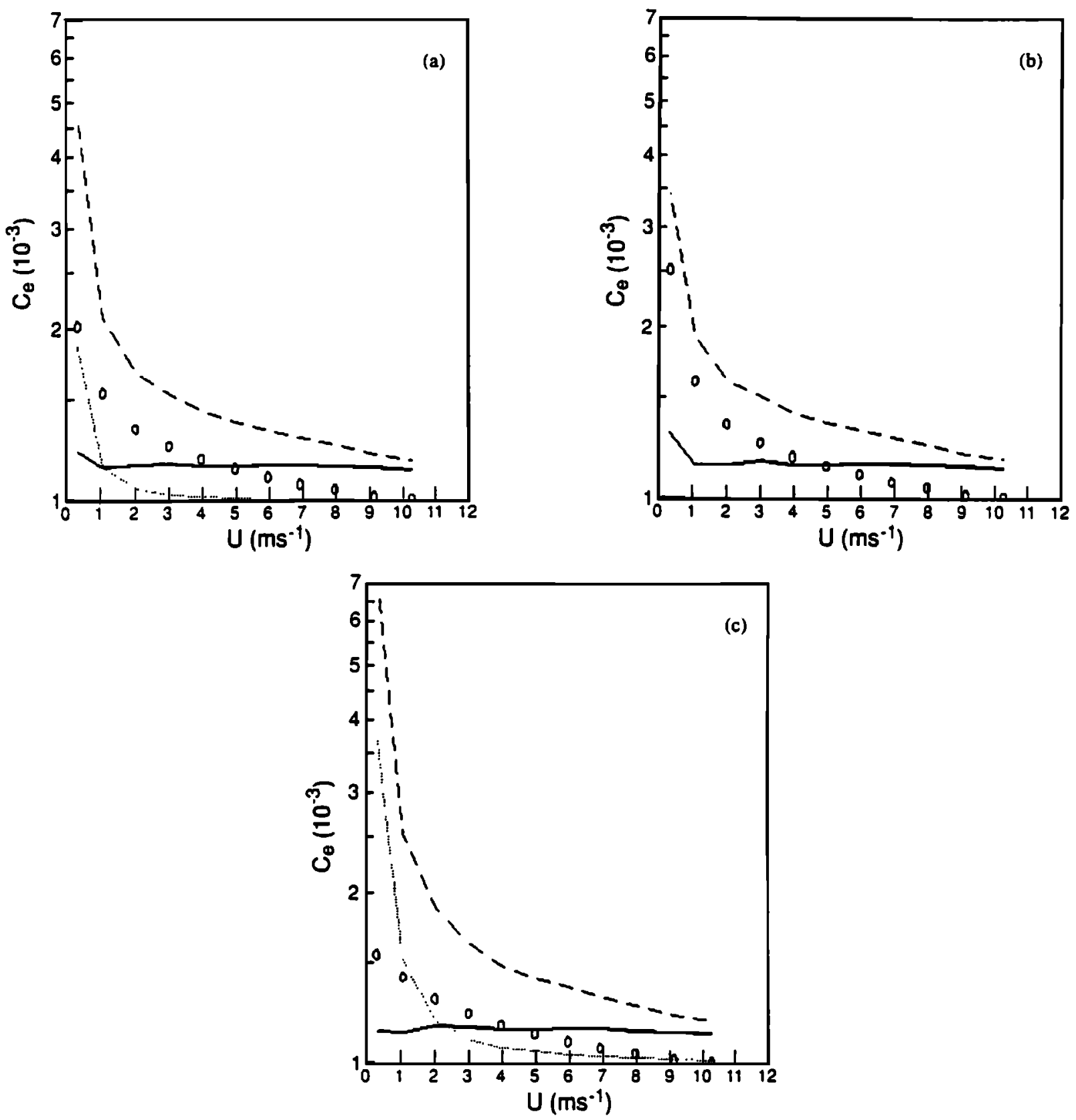

Figure 6. Various components of the COARE 2.0 moisture transfer coefficient as a function of wind speed for the COARE data (a) for $\beta=1.25$, (b) for $\beta=0.1$, and (c) for $\beta=2.5$. The solid line is $C_{e n}$ multiplied by 1000 , the dotted line is the gustiness parameter (equation (29)), the circles are the stability parameter (equation (28)), and the dashed line is stability $\times$ gustiness $\times C_{e n} \times 1000$.

$$
\begin{aligned}
& \text { stability }=\frac{1}{\left[1-\frac{c_{d n}^{1 / 2}}{\kappa} \Psi_{u}(\xi)\right]\left[1-\frac{c_{q n}^{1 / 2}}{a \kappa} \Psi_{h}(\xi)\right]} \\
& \text { gustiness }=\left[1+\left(\beta W_{\bullet} / u\right)^{2}\right]^{1 / 2}
\end{aligned}
$$

Here in (27) the first two terms are thermodynamic constants; the term in brackets represents the small-scale processes attacked in the laboratory investigations; and the last two terms represent surface-layer and boundary layer scale processes.
In Figure 6a we depict the balance of these processes as represented in the COARE 2.0 algorithm for the conditions found by the Moana Wave during COARE. The solid line shows the neutral transfer coefficient; the dotted line shows the gustiness; the circles show the stability effect; and the dashed line shows the product of these three (as per (27)). The lowest wind speed bin shown here is for speeds between 0 and $0.5 \mathrm{~m} \mathrm{~s}^{-1}$. Only 11 usable 50 -min samples from the Moana Wave fell in this bin, with an average wind vector magnitude of $0.33 \mathrm{~m} \mathrm{~s}^{-1}$ and an average latent heat flux of $30 \pm 5 \mathrm{~W} \mathrm{~m}^{-2}$. The COARE 2.0 algorithm yielded a value of $27 \mathrm{~W} \mathrm{~m}^{-2}$. Notice that gustiness and stability effects were about equal, leading to a combined enhancement of the flux 

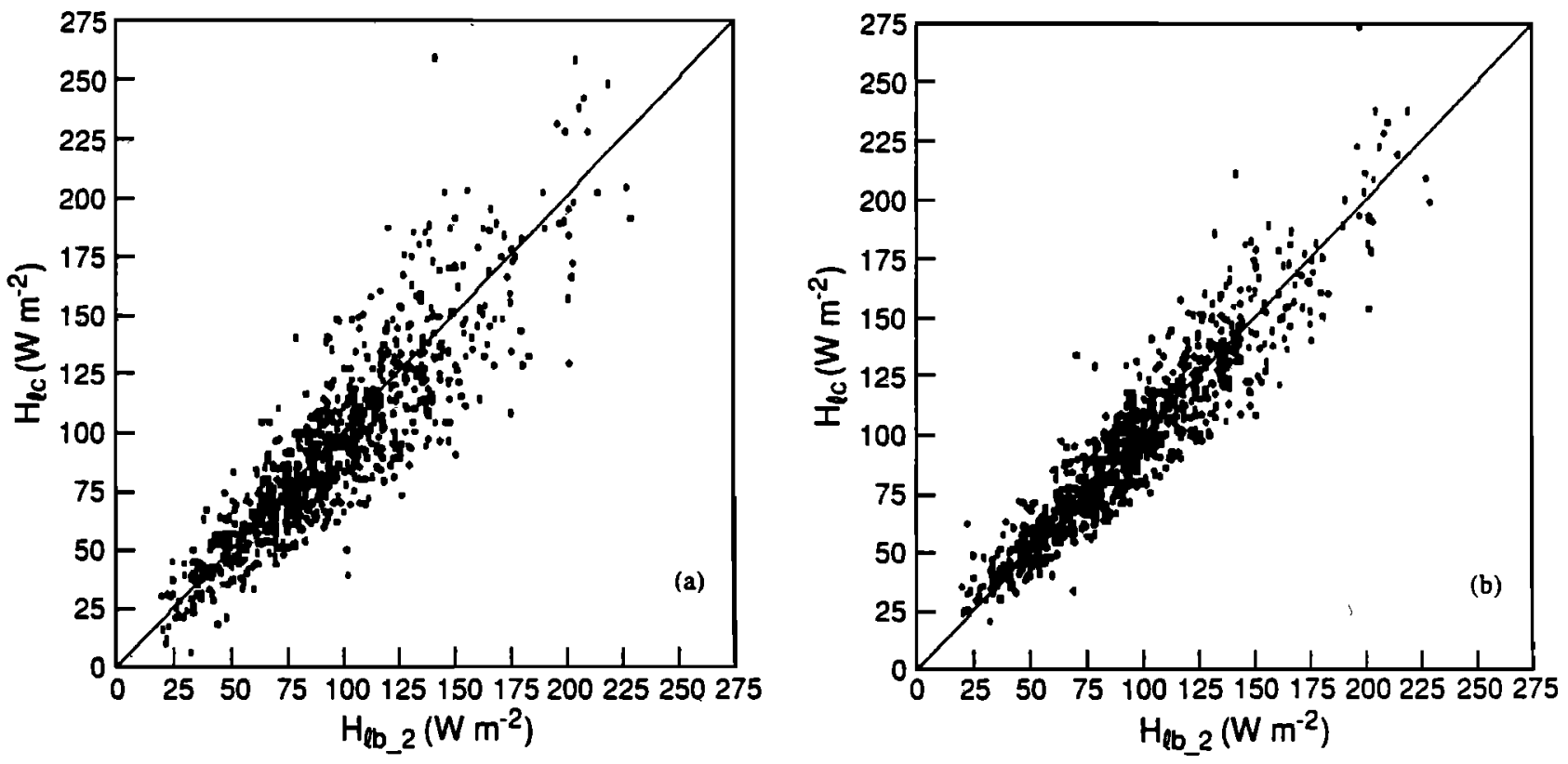

Figure 7. Moana Wave turbulence latent heat flux data versus COARE 2.0 bulk values where the vertical axis is (a) covariance data and (b) the average of covariance and inertial-dissipation data.

of about a factor of 4 . We can return to the past by setting $\beta \approx 0$ and forcing all of the convective effects into the MOS term (Figure 6b). Notice that this has only a modest effect until the wind speed becomes less than $2-3 \mathrm{~m} \mathrm{~s}^{-1}$. Now for $u=0.33 \mathrm{~m} \mathrm{~s}^{-1}$ the algorithm yields a flux of $20 \mathrm{~W} \mathrm{~m}^{-2}$. However, as Godfrey and Beljaars [1991] pointed out, we know that at sufficiently low wind speed, this version of the model must become pathological. By going to the other extreme (setting $\beta=2.5$ ), we can demonstrate that the gustiness and stability effects tend to be compensating. Note in Figure 6c that the increase in the gustiness term is significantly canceled by a reduction in the stability term. Thus a doubling of $\beta$ only leads to an increase in the latent heat flux of $46 \%\left(H_{l}=39 \mathrm{~W} \mathrm{~m}^{-2}\right)$. This is expected because the increased gustiness leads to an increase in $u_{u_{t}}$ and therefore a reduction in the magnitude of $\xi$.

\subsection{Flux Comparisons}

The comparison of covariance and bulk latent heat flux is shown in Figure 7a for the 876 samples that passed the various rejection criteria (relative wind direction within $90^{\circ}$ of the bow, no ship maneuvers, ship not under way at full speed, and no radio interference or Sun or salt contamination on the fast hygrometer). The mean covariance flux for this restricted set is $93.8 \mathrm{~W} \mathrm{~m}^{-2}$; the mean bulk flux is $93.9 \mathrm{~W} \mathrm{~m}^{-2}$. The rms scatter is slightly less than $20 \%$; a similar level of scatter occurs if the inertial dissipation fluxes [Edson et al., 1991] are used for comparison. Much of this scatter is sampling uncertainty in the turbulence measurement. In Figure $7 \mathrm{~b}$ we compare the bulk flux with the average of the covariance and inertial-dissipation fluxes. This reduces the rms scatter to about $12 \%$, a truly remarkable level of consistency, presumably due to the fact that the covariance and inertial dissipation scatter is uncorrelated.

In Figure 8a we show a comparison of bulk and covariance sensible heat values. Here we have added data from the R/P FLIP cruise; we do this because the sensible heat fluxes in COARE were so small that it was difficult to get a reasonable test of the parameterization. Also, because of the sensitivity of temperature measurements to contamination by the ship's heat island, we restricted the data to relative winds within $30^{\circ}$ of the bow. Note the great clot of points in the region between 0 and $5 \mathrm{~W} \mathrm{~m}^{-2}$. The cloud of points scattered outside this clot are primarily caused by radiationinduced errors in the air temperature. The Moana Wave system had an aspirated radiation shield, but intercomparisons with the R/V Franklin showed that it was subject to errors as large as $1.5^{\circ} \mathrm{C}$ in light winds. A crude correction was developed, but it still leaves some residual uncertainty. In a similar graph for just nighttime data (not shown), much of this outer layer of points disappears. By comparing motion-corrected and uncorrelated heat fluxes to bulk fluxes, we found that ship motion significantly affects covariance values for sensible heat flux (but not for latent heat flux), so some of this scatter may be due to inadequate corrections. For the 618 values from COARE meeting the quality-control criteria described above, the average covariance sensible heat flux was $8.2 \mathrm{~W} \mathrm{~m}^{-2}$ and the average bulk value was $5.7 \mathrm{~W} \mathrm{~m}^{-2}$. If we restrict the computation to nighttime data only, the difference narrows to $1.5 \mathrm{~W} \mathrm{~m}^{-2}$. While the scatter shown in Figure 8a is disturbing, the overall effect on the uncertainty of the total surface energy budget is well within the COARE goal. This is illustrated in Figure 8b, where the sensible heat flux is plotted on the same scale as the latent heat flux (Figure 7).

A comparison of inertial-dissipation and covariance stress measurements with bulk estimations is shown in Figure 9. The log-log format emphasizes the dynamic range of stress and the astounding consistency of the 1025 inertialdissipation and bulk values (Figure 9a). There are more points here than in Figures 7 and 8 because hygrometer contamination is irrelevant to this comparison. The covari- 

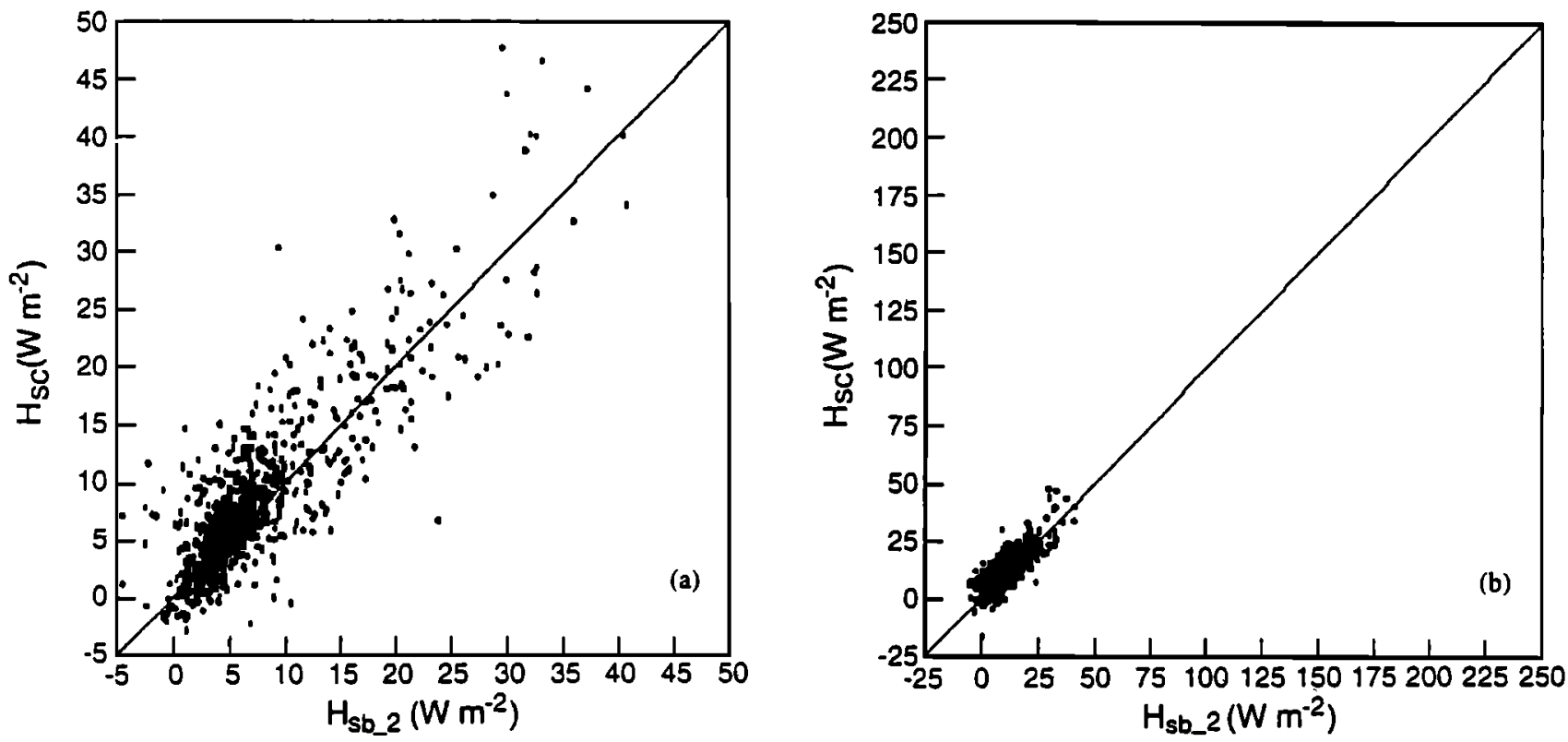

Figure 8. Moana Wave and FLIP covariance sensible heat flux data versus COARE 2.0 bulk values on (a) expanded scale and (b) the same scale as Figure 7.

ance results (Figure 9b) are, to understate, unimpressive. Covariance data are restricted to situations where the relative wind direction was within $30^{\circ}$ of the bow and tilt of the mean velocity vector in the fixed frame was less than $10^{\circ}$ (for a total of 676 points). The same data are depicted in Figure 10 in linear format. The clot of covariance points very near the origin is characteristic of fixed-site measurements of stress over the ocean, where the sampling uncertainty is considerable. However, measurements from fixed platforms and FLIP do not show the large scatter seen here, particularly at higher wind speeds [e.g., Edson et al., 1991]. Whereas occasional spotty Global Positioning System (GPS)

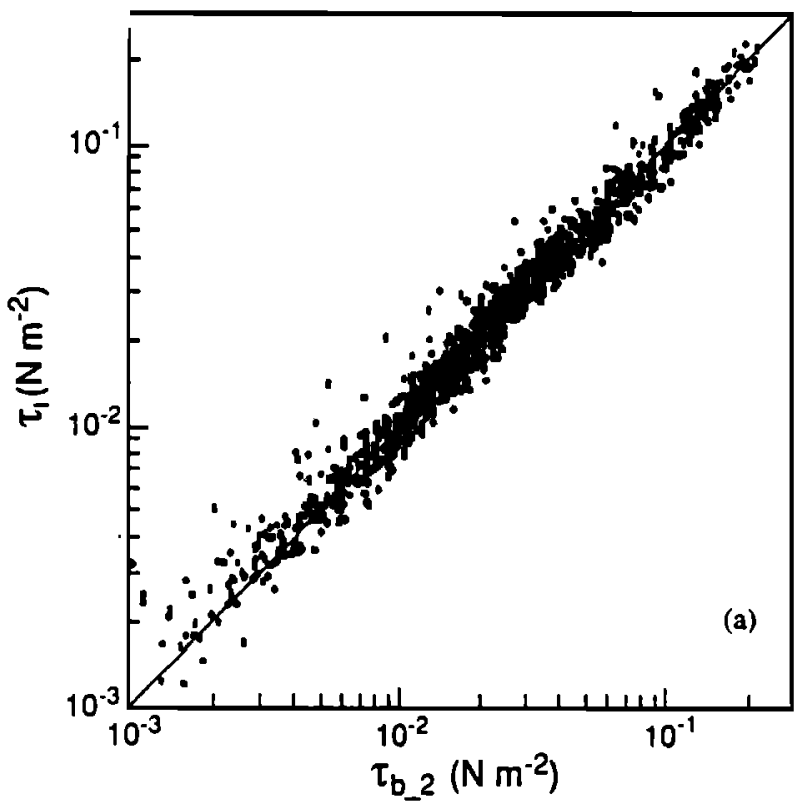

reception and subtle ship maneuvers may cause some of the obvious outliers, the majority of this scatter is believed to be due primarily to inadequate ship motion corrections, particularly for the horizontal wind components, although some contributions from flow distortion cannot be ruled out. The average stress magnitude for the 1025 points is $0.031,0.034$, and $0.033 \mathrm{~N} \mathrm{~m}^{-2}$ for covariance, inertial-dissipation, and bulk methods, respectively. This comparison suggests that the average bias in the covariance stress measurements is no more than $0.002 \mathrm{~N} \mathrm{~m}^{-2}$. Incidentally, for these data the average horizontal-transverse stress was $0.005 \mathrm{~N} \mathrm{~m}^{-2}$, indicating the stress vector is, on average, rotated about $10^{\circ}$

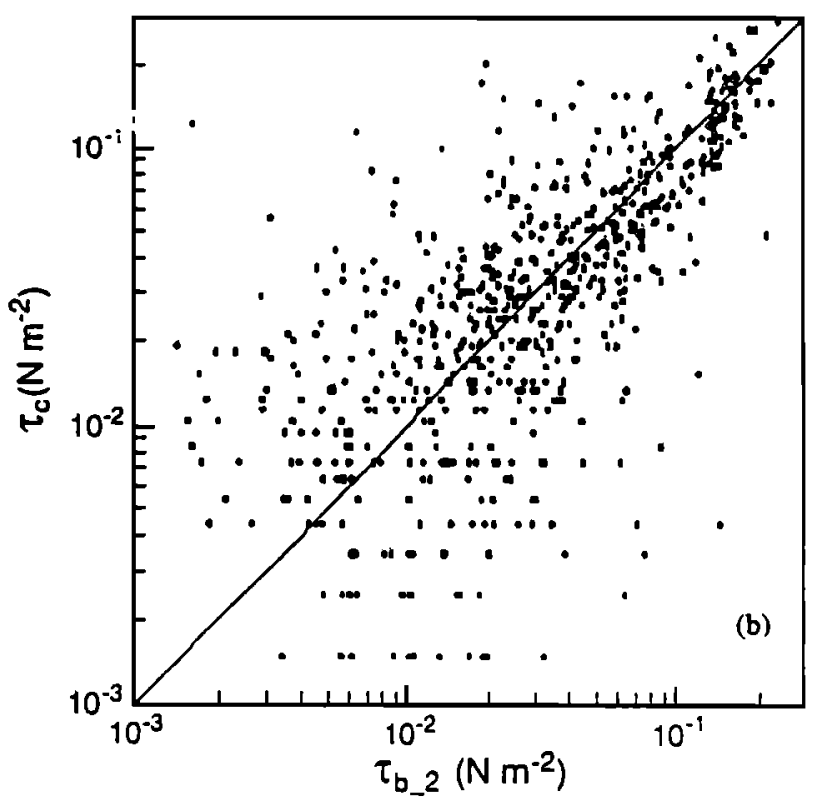

Figure 9. Log-log plot of Moana Wave turbulence stress data versus COARE 2.0 bulk values where the vertical axis is (a) inertial-dissipation turbulence data and (b) covariance turbulence data. 

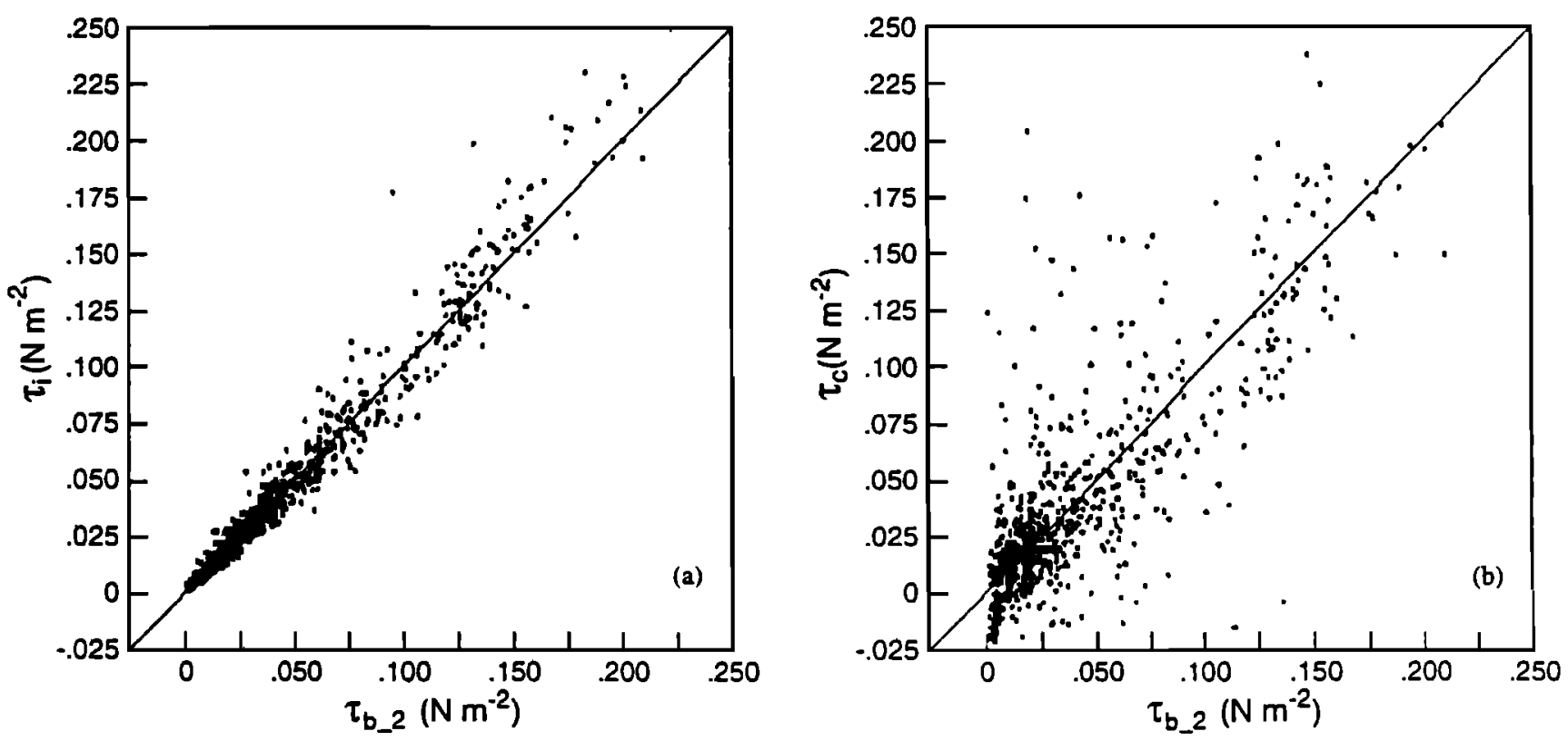

Figure 10. Same as in Figure 9, except for linear-linear axes.

relative to the wind vector. See Geernaert [1990] for a discussion of the orientation of the stress vector relative to the wind vector.

\subsection{Wind Speed Dependence of the Latent Heat Flux}

The mean transfer coefficient comparisons of Figure 2 and the point-by-point flux comparisons of Figure 7 give most of the picture, but the importance of latent heat flux makes scrutiny of the mean wind speed dependence worthwhile. Using the velocity binning method described earlier, we have computed the mean latent heat flux with the same data rejected, as in Figure 7a. The mean wind speed dependence for bulk, covariance, and inertial-dissipation data is shown in Figure 11. Except for an overestimate of the flux in the convective limit by the inertial-dissipation method, the agreement is quite close.

\subsection{Comparisons With Other Measurements}

Whereas the analysis of this paper has featured measurements from the Moana Wave (for the reasons discussed previously), some preliminary data are available from other sources to assess in a crude sense the validity of the present algorithm. One source is the National Center for Atmospheric Research (NCAR) Electra aircraft, which made a number of low-altitude measurements in light wind conditions. Figure 12 shows straightforward comparisons of bulk and covariance fluxes for 174 Electra measurements within $100 \mathrm{~m}$ of the surface. The mean $10-\mathrm{m}$ wind speed for these data is $3.1 \mathrm{~m} \mathrm{~s}^{-1}$, so they emphasize the low wind speed regime. The scatter for latent heat flux is greater than the ship data, while that for stress is less, and sensible heat flux is comparable. The differences are believed to reflect the better sampling of fluxes by the aircraft in these conditions, combined with poorer determinations of the mean parameters for the bulk relationships. Also, because the aircraft is measuring at somewhat greater heights $(30-60 \mathrm{~m})$, there is always the possibility of some deviation from the surface flux values. The mean values for the bulk latent, sensible, and momentum fluxes were $81 \mathrm{~W} \mathrm{~m}^{-2}, 6 \mathrm{~W} \mathrm{~m}^{-2}$, and $0.018 \mathrm{~N} \mathrm{~m}^{-2}$; the corresponding aircraft mean covariance values were $76 \mathrm{~W} \mathrm{~m} \mathrm{~W}^{-2}, 6 \mathrm{~W} \mathrm{~m}^{-2}$, and $0.018 \mathrm{~N} \mathrm{~m}^{-2}$. Note that the aircraft covariance values have not been corrected for possible difference between the flight level and the surface.

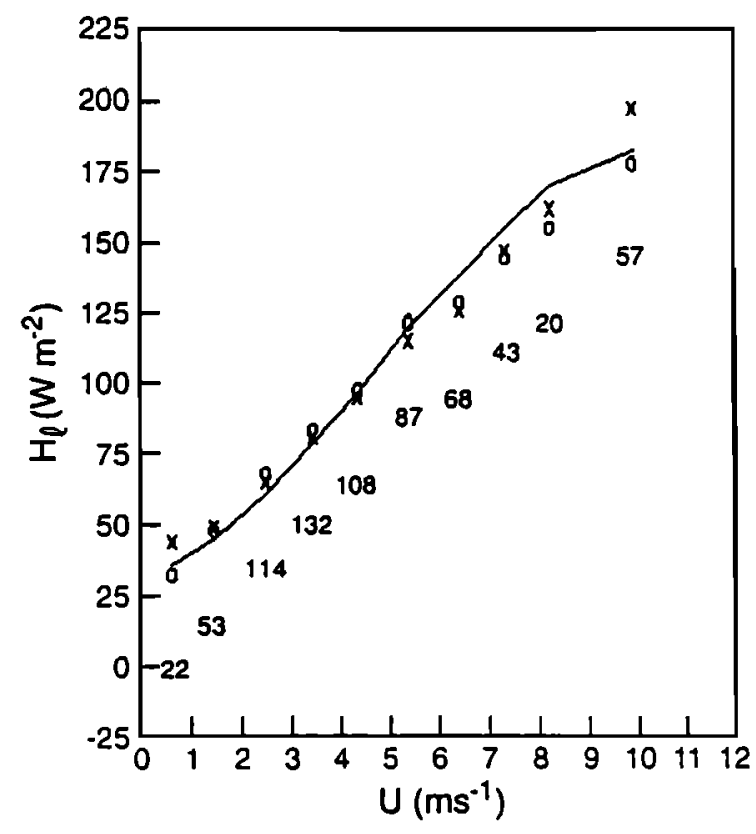

Figure 11. Moana Wave latent heat flux versus wind speed, bin averaged as in Figure 1 . The solid line is the COARE 2.0 bulk value, the crosses are the inertialdissipation value, and the circles are the covariance value. Data are for winds within $90^{\circ}$ of the bow, no ship maneuvers, and no contamination of the fast hygrometer. 

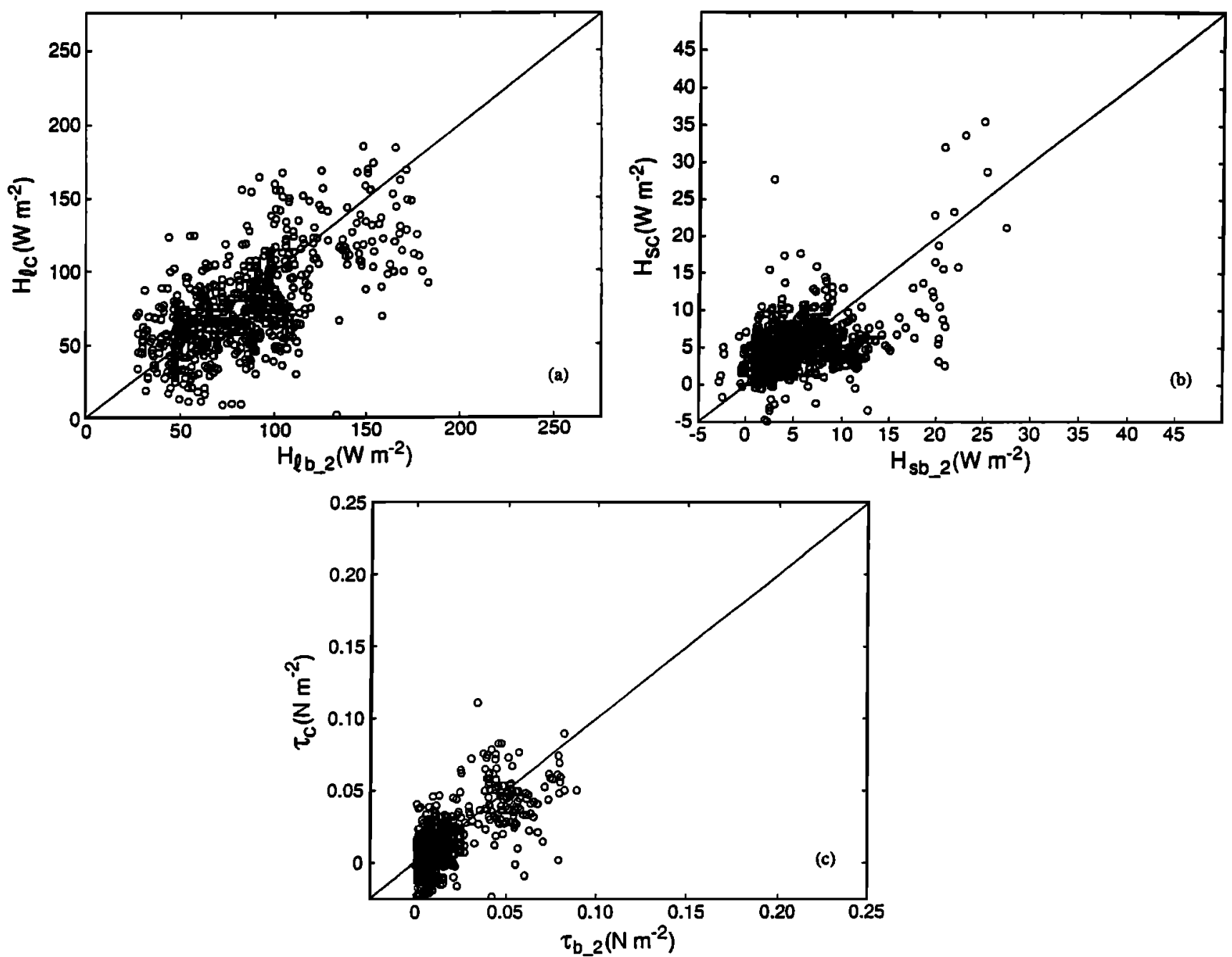

Figure 12. NCAR Electra aircraft flux measurements during various low-altitude runs during COARE, showing covariance versus (a) latent heat flux, (b) sensible heat flux, and (c) stress values.

\section{Conclusions}

Ambitious requirements for flux estimation accuracy in the TOGA COARE program have placed unusual demands on the measurements of bulk variables and the determination of the bulk transfer coefficients. The integration of measurements from numerous ships, buoys, and aircraft requires both an aggressive program of platform intercomparison and a standard bulk algorithm that can serve as a reference point. Given sufficiently accurate measurements of the bulk variables (e.g., section 3.2), the algorithm should deliver estimates of the average surface energy budget with built-in bias not to exceed $10 \mathrm{~W} \mathrm{~m}^{-2}$. Thus, for the purposes of COARE, historical uncertainties in bulk transfer coefficients of the order of $30 \%$ must be resolved; many minor corrections, previously ignored as insignificant, must be reconsidered; and the low wind speed conditions prevalent in the COARE region must be accommodated. Furthermore, to allow the broadest application, the algorithm must permit correction and reconciliation of measurements from less than ideal sampling (e.g., water temperature measurements $2 \mathrm{~m}$ below the surface).
The algorithm described in this paper follows the standard Monin-Obukhov similarity approach for near-surface meteorological measurements. The basic structure is an outgrowth of the Liu-Katsaros-Businger [Liu et al., 1979] method, with various minor modifications. Such modifications include a different specification of the roughness/stress relationship, a gustiness coefficient to account for the additional flux induced by boundary layer scale variability, and profile functions obeying the convective limit, but no adjustment of constants specifying the relationship between the scalar and velocity transfer coefficients. These adjustments typically amount to a $20 \%$ change in the LKB model. Extreme care has been taken in the selection of various geophysical constants (e.g., acceleration of gravity or the von Kármán constant), thermodynamic relationships (e.g., the temperature dependence of the saturation vapor pressure of water), and parameters (e.g., the latent heat of vaporization of water). Additionally, we have considered the contributions of the sensible heat carried by precipitation, the requirement that the net dry mass flux be zero (the so-called Webb correction [Webb et al., 1980]), and the proper specification of the variables in the sensible and latent heat 
fluxes, corrections that amount to only a few watts per square meter but, at least when added to other errors, threaten our ability to meet the COARE guidelines.

Separate models to account for both the cool-skin and warm-layer effects on bulk sea temperature measurements have been integrated into the algorithm. The cool skin represents a few tenths of a kelvin cooling by radiative and turbulent fluxes in the upper millimeter of the ocean; the warm layer may be several kelvin of solar-induced warming in the upper meter. Incidentally, such corrections cannot be incorporated into adjustments of the neutral transfer coefficients, as sometimes is suggested. The warm-layer correction is clearly a function of the depth of the sensor and is not even a pure function of the present conditions but depends on past history. To include an average cool-skin correction into transfer coefficients will increase scatter and lead to systematic errors in different climate zones.

The algorithm has been tuned to fit measurements made on the R/V Moana Wave in the three different cruise legs made during COARE. These measurements yielded 1622 fifty-min averages of fluxes and bulk variables. Restricting the data to selected periods to eliminate poor relative wind directions or contamination by rain, Sun, salt, and ship's maneuvers reduced the sample by one third to one half (depending on the flux of interest), but this still provides a substantially larger data set than has typically been available in the past. This allowed us to obtain reliable estimates of the Charnock [1955] constant $(\alpha=0.011)$ and the gustiness parameter $(\beta=1.25)$. The peak in humidity roughness Reynolds number $R_{q}$ for $R_{r}=0.8$ predicted by LKB was not observed; rather, $R_{q}$ is roughly independent of $R_{r}$. However, the new roughness/stress specification has significantly reduced the famous bump in $C_{e n}$ at a wind speed of about $6 \mathrm{~m} \mathrm{~s}^{-1}$ in the LKB scalar exchange coefficients [see Bradley et al., 1993]. The addition of the gustiness velocity tends to suppress the hydrostatic stability effects and reduce the sensitivity to the parameter choices.

While the algorithm has been tuned to the Moana Wave measurements, certain aspects of the comparison of bulk and turbulent measurements of the fluxes are quite interesting. The high correlation and small scatter of the combined covariance and inertial-dissipation latent heat flux and the inertial-dissipation stress with corresponding bulk-derived values are remarkable for flux measurements, in general, and especially for ship-based measurements. On the other hand, the covariance versus bulk stress comparison is notably poor, presumably a tribute to the particular sensitivity of covariance stress measurements to the relatively crude methods used to compensate for ship motion in real time. The comparison of the algorithm with covariance fluxes from the NCAR Electra (Figure 12) did not reveal any obvious problems, but the data are really too scattered to be considered a definitive verification of the fine details. Also, because the Moana Wave used a floating thermometer to measure water temperature in the upper few centimeters of the ocean and the Electra used an IR surface-temperature sensor, the warm-layer part of the bulk algorithm is not severely tested in these comparisons. This has, however, been done using other information, as described by Fairall et al. [1996]. Regardless, a more careful verification and modification of the complete algorithm will be undertaken over the next few years as motion-corrected and inertialdissipation fluxes from the R/V Franklin, R/V Wecoma, and
R/V Hakuho-Maru become available. The applicability of data from the four flux-measuring aircraft participating in COARE to this problem will become apparent as attempts to reconcile their bulk and turbulence variable measurements are completed.

We expect that the algorithm will be applied to bulk measurements from numerous ships and buoys in the COARE region. As intercomparisons between ships and aircraft with these buoys become available, it will become clear if the $10 \mathrm{~W} \mathrm{~m}^{-2}$ COARE guideline can be met more generally. Because the model has been developed from measurements that include midlatitude field programs, we anticipate that it is applicable outside the COARE climate regime, even into polar regions. Finally, it is worth stating that this model has been optimized to convert point measurements of bulk variables on timescales of $10 \mathrm{~min}$ to 1 hour into equivalently sampled fluxes. Because of the scale dependence of some crucial parameterizations such as that for gustiness, we expect that it can be incorporated into numerical models of equivalent scale but not, at this stage of development, into large-scale climate models.

Acknowledgments. This work was supported by the joint NSF/NOAA Climate and Global Change Program, the Office of Naval Research, the Department of Defense Applied Sensor Assessment Program, and the CSIRO Climate Change Research Program. The authors wish to recognize the crews of the R/V Moana Wave, R/V Franklin, and the NCAR Electra for their outstanding efforts. C. Fairall, J. Edson, and G. S. Young wish to thank Cat Russell, Dave Gregg, Jesse Leach, Lynn May, and Norbert (Ski) Szczepczynski for their cheerful and necessary contributions. We are particularly grateful to Meghan Cronin for her painstaking evaluation of the bulk algorithm at each stage of its development.

\section{References}

Andreas, E. L., Thermal and size evolution of sea spray droplets, Rep. 89-11, 39 pp., U.S. Army Corps of Eng. Cold Reg. Res. and Eng. Lab., Hanover, N.H., 1989.

Blanc, T. V., Variation of bulk-derived surface flux, stability, and roughness results due to the use of different transfer coefficient schemes, J. Phys. Oceanogr., 15, 650-669, 1985.

Blanc, T. V., The effect of inaccuracies in weather-ship data on bulk-derived estimates of flux, stability, and sea-surface roughness, J. Atmos. Oceanic Technol., 3, 12-26, 1986.

Blanc, T. V., Accuracy of bulk-method-determined flux, stability, and sea surface roughness, J. Geophys. Res., 92, 3867-3876, 1987.

Bradley, E. F., P. A. Coppin, and J. S. Godfrey, Measurements of sensible and latent heat flux in the western tropical Pacific Ocean, J. Geophys. Res., 96, 3375-3389, 1991.

Bradley, E. F., J. S. Godfrey, P. A. Coppin, and J. A. Butt, Observations of net heat flux into the surface mixed layer of the westem equatorial Pacific Ocean, J. Geophys. Res., 98, 22,52122,532, 1993.

Brook, R. R., The influence of water vapor fluctuations on turbulent fluxes, Boundary Layer Meteorol., 15, 481-487, 1978.

Brutsaert, W., Evaporation into the Atmosphere, 299 pp., D. Reidel, Norwell, Mass., 1982.

Businger, J. A., The fluxes of specific enthalpy, sensible heat, and latent heat near the Earth's surface, J. Atmos. Sci., 39, 1889$1892,1982$.

Businger, J. A., Evaluation of the accuracy with which dry deposition can be measured with current micrometeorological techniques, J. Clim. Appl. Meteorol., 25, 1100-1123, 1986.

Businger, J. A., J. C. Wyngaard, Y. Izumi, and E. F. Bradley, Flux profile relationships in the atmospheric surface layer, J. Atmos. Sci., 28, 181-189, 1971. 
Caldwell, D. R., and W. P. Elliott, Surface stresses produced by rainfall, J. Phys. Oceanogr., 1, 145-148, 1971.

Charnock, H., Wind stress on a water surface, $Q$. J. R. Meteorol. Soc., 81, 639, 1955.

Chertock, B., C. W. Fairall, and A. B. White, Surface-based measurements and satellite retrievals of broken cloud properties in the equatorial Pacific, J. Geophys. Res., 98, 18,489-18,500, 1993.

Coppin, P. A., E. F. Bradley, I. J. Barton, and J. S. Godfrey, Simultaneous observations of sea surface temperature in the western equatorial Pacific Ocean by bulk, radiative, and satellite methods, J. Geophys. Res., 96, 3401-3409, 1991.

Edson, J. B., C. W. Fairall, P. G. Mestayer, and S. E. Larsen, A study of the inertial-dissipation method for computing air-sea fluxes, J. Geophys. Res., 96, 10,689-10,711, 1991.

Emery, W. J., Y. Yu, G. A. Wick, P. Schluessel, and R. W. Reynolds, Correcting infrared satellite estimates of sea surface temperature for atmospheric water vapor attenuation, J. Geophys. Res., 99, 5219-5236, 1994.

Fairall, C. W., and J. B. Edson, Recent measurements of the dimensionless turbulent kinetic energy dissipation function over the ocean, paper presented at the Second Int. Conf. on Air-Sea Interaction and Meteorology and Oceanography of the Coastal Zone, Am. Meteorol. Soc., Lisbon, Portugal, Sept. 22-27, 1994.

Fairall, C. W., and M. McPhaden, A ship-buoy comparison of bulk meteorological measurements and implications for surface flux estimates, paper presented at the Third Scientific Meeting of the Oceanography Society, The Oceanogr. Soc., Seattle, Wash., April 13-16, 1993.

Fairall, C. W., and A. B. White, A ship-based system for direct surface flux and remote boundary-layer measurements over the ocean, in The Air-Sea Interface, edited by M. A. Donelan, W. H. Hui, and W. J. Plant, Univ. of Toronto Press, Toronto, Ont., Canada, 1994.

Fairall, C. W., and G. S. Young, A field evaluation of shipboard performance of an infrared hygrometer, paper presented at the 7th AMS Symposium on Meteorological Observations and Measurements, Am. Meteorol. Soc., New Orleans, La., 1991.

Fairall, C. W., J. B. Edson, S. E. Larsen, and P. G. Mestayer, Inertial-dissipation air-sea flux measurements: A prototype system using real-time spectral computations, J. Atmos. Oceanic Technol., 7, 425-453, 1990.

Fairall, C. W., J. Kepert, and G. J. hiolland, The effect of sea spray on surface energy transports over the ocean, Global Atmos. Ocean Syst., 2, 121-142, 1994.

Fairall, C. W., E. F. Bradley, J. S. Godfrey, G. A. Wick, J. B. Edson, and G. S. Young, Cool-skin and warm-layer effects on sea surface temperature, J. Geophys. Res., in press, 1996.

Fleagle, R. G., and J. A. Businger, An Introduction to Atmospheric Physics, 432 pp., Academic, San Diego, Calif., 1980.

Frank, W. M., and G. D. Emmitt, Computation of vertical total energy fluxes in a moist atmosphere, Boundary Layer Meteorol., 21, 223-230, 1981.

Fujitani, T., Method of turbulent flux measurement on a ship by using a stable platform system, J. Meteorol. Soc. Jpn., 36, 157-170, 1985

Fujitani, T., Turbulent transport mechanism in the surface layer over the tropical ocean, J. Meteorol. Soc. Jpn., 70, 795-810, 1992.

Garratt, J. R., Review of drag coefficients over oceans and continents, Mon. Weather Rev., 105, 915-929, 1977.

Garratt, J. R., The Atmospheric Boundary Layer, 316 pp., Cambridge Univ. Press, New York, 1992.

Geernaert, G. L., Bulk parameterizations for the wind stress and heat fluxes, in Surface Waves and Fluxes, vol. 1, edited by G. L. Geernaert and W. J. Plant, pp. 91-172, Kluwer Academic, Norwell, Mass., 1990.

Godfrey, J. S., and A. C. M. Beljaars, On the turbulent fluxes of buoyancy, heat, and moisture at the air-sea interface at low wind speeds, J. Geophys. Res., 96, 22,043-22,048, 1991.

Golitsyn, G. S., and A. A. Grachev, Free convection of multicomponent media and parameterization of air-sea interaction at light winds, Ocean Air Interactions, I, 57-78, 1986.

Gosnell, R., C. W. Fairall, and P. J. Webster, The sensible heat of rainfall in the tropical ocean, J. Geophys. Res., 100, 18,437$18,442,1995$.

Greenhut, G. K., and S. J. S. Khalsa, Bulk transfer coefficients and dissipation-derived fluxes in low wind speed conditions over the western equatorial Pacific Ocean, J. Geophys. Res., 100, 857863, 1995.

Hare, J. E., Shipboard eddy-covariance measurements of the turbulent fluxes of heat, moisture, and momentum, M.S. thesis, 207 pp., Pa. State Univ., University Park, 1992.

Hare, J. E., J. B. Edson, and C. W. Fairall, Progress on real-time covariance measurements of air-sea fluxes from ships and buoys, paper presented at the Tenth AMS Symposium on Turbulence and Diffusion, Am. Meteorol. Soc., Portland, Ore., 1992.

Hogstrom, U., Nondimensional wind and temperature profiles in the atmospheric surface layer: A re-evaluation, Boundary Layer Meteorol., 42, 55-78, 1988.

Kraus, E. B., and J. A. Businger, Atmosphere-Ocean Interaction, 352 pp., Oxford Univ. Press, New York, 1994.

Larsen, S. E., J. B. Edson, C. W. Fairall, and P. G. Mestayer, Measurement of temperature spectra by a sonic anemometer, J. Atmos. Oceanic Technol., 10, 345-354, 1993.

Liu, W. T., An overview of bulk parameterization and remote sensing of latent heat flux in the tropical ocean, paper presented at the Western Pacific International Meeting and Workshop on TOGA COARE, Inst. Fr. de Rech. Sci. pour le Dev. en Coop. (ORSTOM), Noumea, New Caledonia, 1989.

Liu, W. T., K. B. Katsaros, and J. A. Businger, Bulk parameterization of the air-sea exchange of heat and water vapor including the molecular constraints at the interface, J. Atmos. Sci., 36, 1722-1735, 1979.

Lukas, R., Observations of air-sea interactions in the western Pacific warm pool during WEPOCS, paper presented at the Western Pacific International Meeting and Workshop on TOGA COARE, Inst. Fr. de Rech. Sci. pour le Dev. en Coop. (ORSTOM), Noumea, New Caledonia, 1989.

Miller, M. J., A. C. M. Beljaars, and T. N. Palmer, The sensitivity of the ECMWF model to the parameterization of evaporation from the tropical oceans, J. Clim., 5, 418-434, 1992.

Nordeng, T. E., On the wave age dependent drag coefficient and roughness length at sea, J. Geophys. Res., 96, 7167-7174, 1991.

Oost, W. A., C. W. Fairall, J. B. Edson, S. D. Smith, R. J. Anderson, J. A. B. Wills, K. B. Katsaros, and J. DeCosmo, Flow distortion calculations and their application in HEXMAX, J. Atmos. Oceanic Technol., 11, 366-386, 1993.

Panofsky, H. A., and J. A. Dutton, Atmospheric Turbulence, 397 pp., Wiley-Interscience, New York, 1984.

Price, J. F., R. A. Weller, and R. Pinkel, Diurnal cycling: Observations and models of the upper ocean response to diumal heating, cooling, and wind mixing, J. Geophys. Res., 91, 8411-8427, 1986.

Saunders, P. M., The temperature of the ocean-atmosphere interface, J. Atmos. Sci., 24, 269-273, 1967.

Schluessel, P., W. J. Emery, H. Grassl, and T. Mammen, On the bulk-skin temperature difference and its impact on satellite remote sensing of the sea surface temperature, J. Geophys. Res., 95, 13,341-13,356, 1990.

Schumann, U., Minimum friction velocity and heat transfer in the rough surface layer of a convective boundary layer, Boundary Layer Meteorol., 44, 311-326, 1988.

Smith, S. D., Coefficients for sea surface wind stress, heat flux, and wind profiles as a function of wind speed and temperature, J. Geophys. Res., 93, 15,467-15,472, 1988.

Stull, R. B., A convective transport theory for surface fluxes, J. Atmos. Sci., 51, 3-22, 1994.

Sverdrup, H. U., M. W. Johnson, and R. H. Fleming, The Oceans, 1087 pp., Prentice-Hall, Englewood Cliffs, N.J., 1942.

Sykes, R. I., D. S. Henn, and W. S. Lewellen, Surface-layer description under free convective conditions, $Q$. J. R. Meteorol. Soc., 118, 363-374, 1993.

Tsukamoto, O., E. Ohtaki, H. Ishida, M. Horiguchi, and Y. Mitsuta, On-board direct measurements of turbulent fluxes over the open sea, J. Meteorol. Soc. Jpn., 68, 203-211, 1990.

Webb, E. K., G. I. Pearman, and R. Leuning, Correction of flux 
measurements for density effects due to heat and water vapor transport, Q. J. R. Meteorol. Soc., 106, 85-100, 1980.

Webster, P. J., and R. Lukas, TOGA COARE: The coupled ocean atmosphere response experiment, Bull. Am. Meteorol. Soc., 73, 1377-1416, 1992.

Woodcock, A. H., Surface cooling and streaming in shallow, fresh, and salt water, J. Mar. Res., 4, 153-161, 1941.

World Climate Research Program, Scientific plan for the TOGA Coupled Ocean-Atmosphere Response Experiment, in World Clim. Res. Program Publ. Ser., WMO/TD-64, 3, addendum, 105 pp., World Meteorol. Organ., Geneva, 1990.

$\mathrm{Wu}, \mathrm{J}$., Laboratory studies of wind-wave interactions, J. Fluid Mech., 34, 91-111, 1968.

Wyngaard, J. C., Scalar fluxes in the planetary boundary layer: Theory, modeling, and measurement, Boundary Layer Meteorol., 50, 49-75, 1990.

Young, G. S., D. R. Ledvina, and C. W. Fairall, Influence of precipitating convection on the surface energy budget observed during a Tropical Ocean Global Atmosphere pilot cruise in the tropical westem Pacific Ocean, J. Geophys. Res., 97, 9595-9603, 1992.
Young, G. S., S. M. Perugini, and C. W. Fairall, Convective wakes in the equatorial western Pacific during TOGA, Mon. Weather Rev., 123, 110-123, 1995.

E. F. Bradley, Centre for Environmental Mechanics, CSIRO, Canberra, A.C.T. 2601 Australia. (email: bradley@python.enmech. csiro.au)

J. B. Edson, A.O.P.\&E. Department, Woods Hole Oceanographic Institution, Woods Hole, MA 02543. (email: jedson@airsea2.whoi. edu)

C. W. Fairall, Environmental Technology Laboratory, NOAA, 325 Broadway, Boulder, CO 80303 . (email: cfairall@etl.noaa.gov)

D. P. Rogers, Physical Oceanography Research Division, Scripps Institute of Oceanography, MS/0203, 3500 Gilman Drive, La Jolla, CA 92093. (email: drogers@ucsd.edu)

G. S. Young, Department of Meteorology, Pennsylvania State University, University Park, PA 16802. (email: gyoung@ems.psu. edu)

(Received April 3, 1995; revised August 28, 1995; accepted September 6, 1995.) 